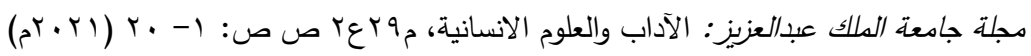

$$
\begin{aligned}
& \text { DOI:10.4197/Art.29-2.1 }
\end{aligned}
$$

\title{
الصياد في كمينه: صورة الحكيم في النكت الشعبية بمواقع التواصل الاجتماعي
}

\author{
د. دادل خميس الزهراني \\ أستاذ النقد الحديث المشارك، قسم اللغة العربية وآدابها، جامعة الملك عبدالعزيز بجدة. \\ akalzhrani@kau.edu.sa
}

مستخلص. ينظر هذا البحث إلى صورة 'الحكيم' في النكت الثعبية المنتشرة في مواقع التواصل الاجتماعي، وخصوصاً (تطبيق الواتس آب)، بثيء من التحليل، هادفاً إلى معرفة التغيرات الطارئة على صورة 'الحكيم، في هذه النكت.

تمثل (نكت الحكيم) واحدة من الظواهر الثقافية البارزة في منصات الإعلام الجديد، ويظهر الحكيم في هذه النكت مختلفاً عن صورته النمطية في الثقافة العربية، التي تربطه بالوقار والحكمة وصاحب السلطة المطلقة على فن القول. يفترض الباحث أن هذه النكت التي تعكس صورة غير مألوفة عن مكانة الحكيم ووظيفته تخبئ خلفها خطاباً يستحق فئه النظر والدراسة. لذلك يقوم البحث بتحليل بنية هذه النكت، ومحاولة ربطها بالظاهرة الثقافية العامة المتمثلة في مواقع التواصل الاجتماعي. ويأتي موضوع هذا البحث ضمن اهتمامات النقد الثقافي الذي يتتاول الظواهر الثقافية والأدبية وعلاقتها بالجماهير، محاولاً استخلاص العوامل المكونة لشعبية هذه الظواهر والقوى المحركة لها. ينظر النقد الثقافي إلى (النكت) باعتبارها

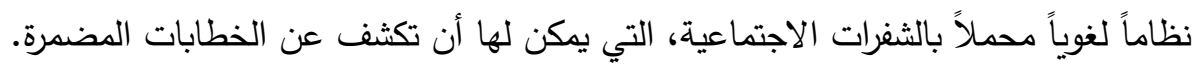
كلمات مفتاحية: نكتة، مواقع التواصل الاجتماعي، خطاب، نقد.

على صورة 'الحكيم، ، ومحاولة تحليل ما يمكن أن تمثله التغييرات التي طرأت على تلك الصورة. يحضر الحكيم في الثقافة العربية، وفي ثقافات أخرى، بوصفه 'مؤسسة رسمية' ذات سلطة مطلقة على الحكمة التي تعد خلاصة التجربة الإنسانية، لكن هذه

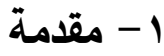

يتناول هذا البحث صورة 'الحكيم، في الطُرف الاجتماعية، (أو النكت الثعبية كما يطلق عليها)، المتداولة في وسائل التثنية الحديثة ومنصات الإعلام الجديد. ويهدف البحث إلى قراءة التحول الذي طرأ 
والسلطوية الهرمية".". من هنا يسعى النقد الثقافي لتسليط الضوء على هذا النظام اللغوي، في محاولة لفك رموزه، والكثف عما يخبئه من خطابات وأسئلة. وسيكون تحليل هذه 'النكت، اعتماداً على منهج تحليل

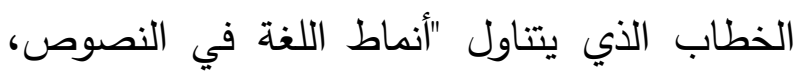
ويهتم بالعلاقة بين اللغة والسياقات الاجتماعية والثقافية المستعملة فيها"، "' كما يرى براين بالتزديج في ولئي

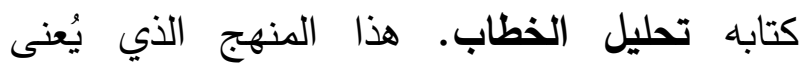

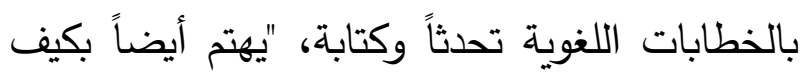

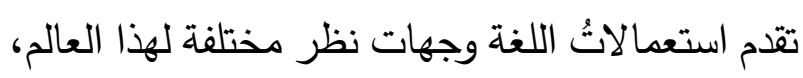

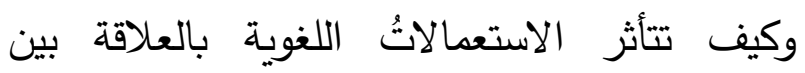
المتشاركين في الحديث، وكيف تؤثر على الهويات والعلاقات الاجتماعية. كما أنه يهتم أيضاً بكيفية بناء

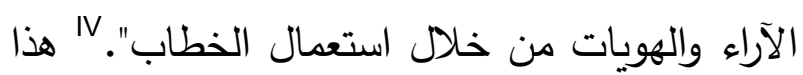
يعني أن تحليل الخطاب "يقود إلى مناقشة الرؤية

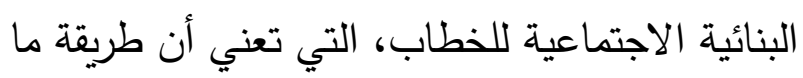

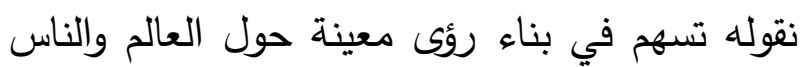
وأنفسنا".

\section{r - ب النكتة: المفهوم والوظيفة}

ترتبط الحكمة في الثقافات عموماً بالعقل والمعرفة الواسعة والتجربة العريضة التي تساعد على إصدار

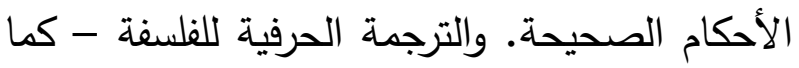
هو شائع ومعروف - تعني (حب الحكمة). وقد تباينت

(Berkeley \& LA: Universoty of California Press, 1991) p. 303.

دالبالتريدج، براين، تحليل الخطاب، ترجمة: عبدالرحمن الفهد، (الرياض:

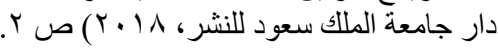

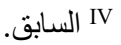

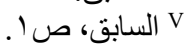

النكت تمثل انقلاباً غير مسبوق على هذه السلطة، حين تعكس لنا صورة مختلفة تماماً، تخبئ خلفها خطاباً يستحق النظر والدراسة. ويأتي موضوع هذا البحث ضمن اهتمامات النقد ولاتئن الثقافي الذي يتناول الظواهر الثقاف/اجتماعية وعلاقتها بالجماهير ، ناظراً في العوامل المكونة لشعبية تلك

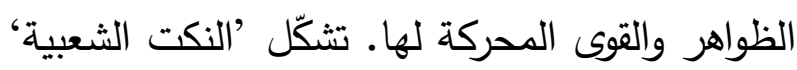
ظاهرة تستحق الدراسة؛ ليس لحجم قبولها الجماهيري

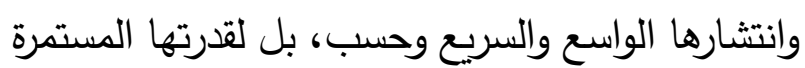
على التجدد والتكيف مع طبيعة الظروف الاجتماعية

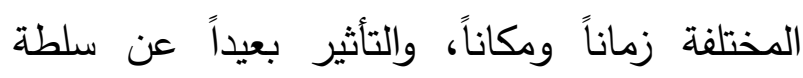
المؤسسة الرسمية، وذلك لأنها تدخل ضمن "الفعل ونلئ الجماهيري والثقافي [الذي] يقع تحت تأثير ما هو غير لانيل رسمي"، مثلها مثل الأغنية العصرية، والإشاعة، والمسلسلات التلفزيونية، كما يؤكد الناقد عبدالله الغذامي، في كتابه (النقد الثقافي: قراءة في الأنساق الثقافية العربية). من هنا ينظر النقد الثقافي إلى (النكت) باعتبارها

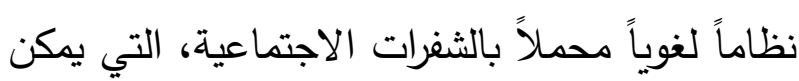

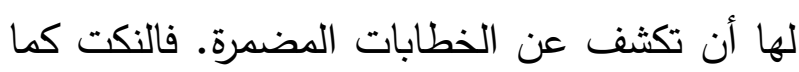
ترى الناقدة الثقافية ماري دوقلاس "ترفض التصنيف والتسلسل الهرمي"، ولذلك "فهي رموز دقيقة للتعبير عن المجتمع - في هذا السياق - الخالي من التمييز

الغذامي، عبدالله، النقل الثقافي: قراءة في الأنساق الثقافية العربية،

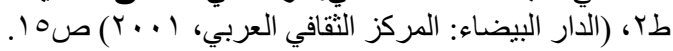
IIDaughlas, Mary, “Jokes," Rethinking Popular Culture: Contempory Perspectives in Cultural Studies, ed. Chandra Mukerji \& Michael Schudson, 
(التهكم السقراطي)، نسبة إلى الفيلسوف الإغريقي

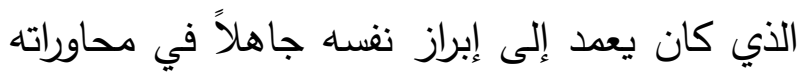

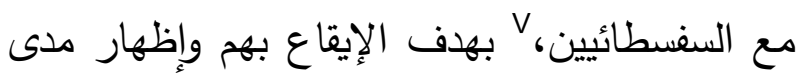
جهلهم.VI ويرى عبدالحميد شاكر أن اهتمام كبار الفلاسفة يأتي لوجود ارتباط بين فسلفاتهم وأفكارهم

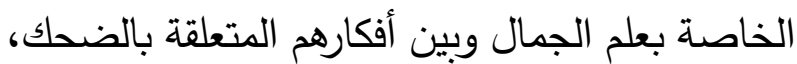

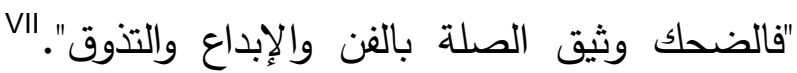
ويعطي شاكر مثالاً -من عدة أمثلة يحشدها في واليداع والثن كتابه- بالفيلسوف 'الضاحك، ديمقريطس الذي "كان يلجأ إلى الضحك [على حماقات الجنس البشري]، كوسيلة ذات طبيعة جيدة تساعده على التحمل

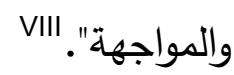

وينقل أبو إسحاق القيرواني في فصل بعنوان (حاجة أهل الأدب إلى ظريف المضحكات) عن الأصمعي

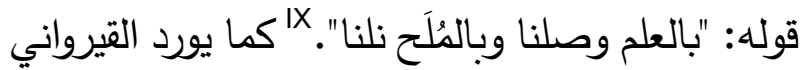

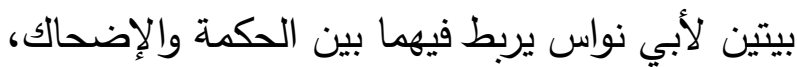
يقول فيهما:

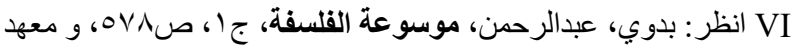

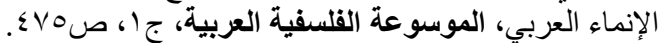

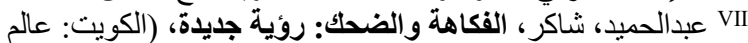

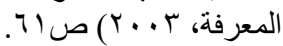

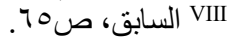

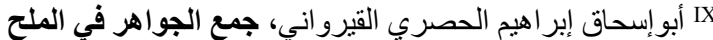
و النوادر، تحقيق محمد العزازي (بيروت: دار الكتب العربية، وجــ (الهـ)
آراء المفسرين في معنى الحكمة في قوله تعالى: (يؤتِّي

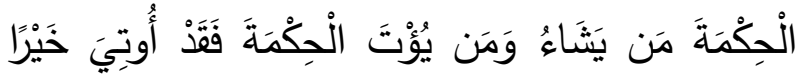

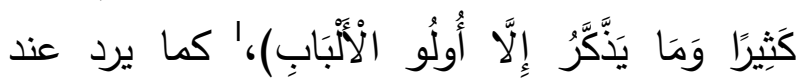
الطبري، بين العلم، والعقل، والفقه بالقرآن، والإصابة الإلهاب في القول والفعل (من هنا خصها بعضهم بالنبوة)." من هنا يورد ابن منظور عدداً من التعريفات الخاصة بمفهوم 'الحكيم'، فالرجل الحكيم هو العدل المتقن

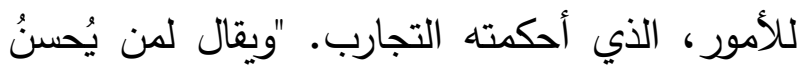
دقائق الصناعات ويتقنها: حكيم.... والحكيم العالمِ وصاحب الحكمة"." وقد عرّف ابن القيم الحكمة بأنها "فعلُ ما ينبغي على الوجه الذي ينبغي في الوقت الذي لني IV ينبغي" من هنا ارتبطت صورة الحكيم في الأذهان بقول الصواب وفعله، وأنه الإنسان الذي يملك الدقومات الكافية التي تؤهله للإفادة من خلاصة تجاربه الإنسانية، وتجارب الآخرين، وتقديمها لعامة الناس للإفادة منها. هذه المقومات تجعله يسيطر على المعرفة، وعلى وسائل تقديمها للناس، حتى حين يتربط ليط الأمر بالسخرية والضحك. وقد ارتبطت السخرية والضحك بالحكمة منذ القدم، إذ تورد كتب الفسلفة طريقة من طرق السخرية تدعى

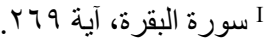

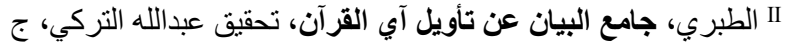

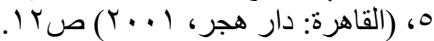

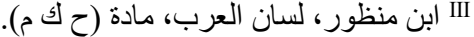

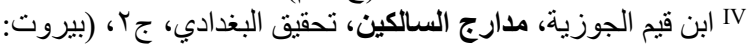

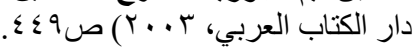

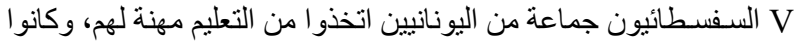

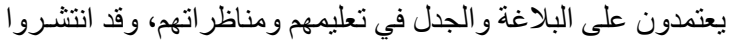

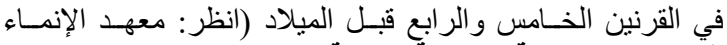

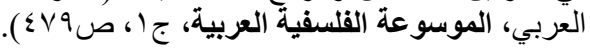




$$
\begin{aligned}
& \text { "إني أنا الرجل الحكيم بطبعه *** * ويزيد في عامي حكاية من حكى }
\end{aligned}
$$

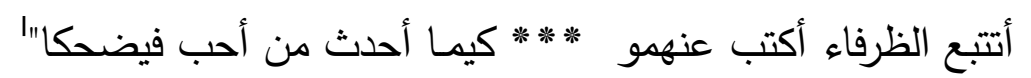

وهكذا يظل الحكيم مسيطراً على المعرفة وعلى المنهج؛ كان "أول من استعمل النكتة بمعنى التعليق الساخر

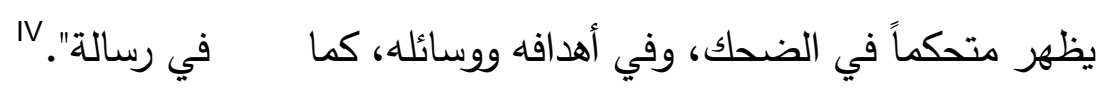
أنه الثخص الذي يضع الكمين في القصة الظريفة ويعرّف الفيلسوف الألماني شوبنهاور النكتة بأنها وفي النكتة، وهو الذي يَضحك، ويُضحِكُ الناس على "محاولة لإثارة الضحك على نحو قصدي، من خلال

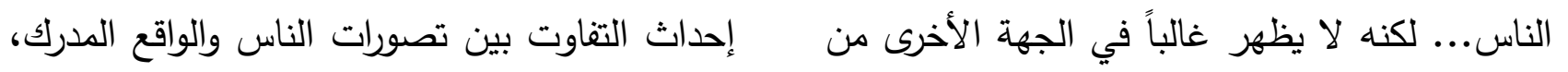

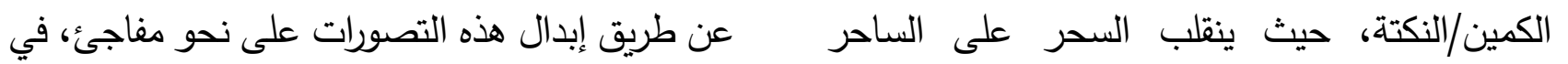

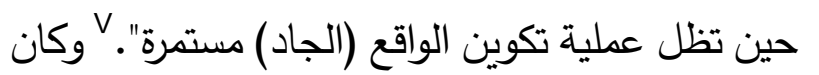

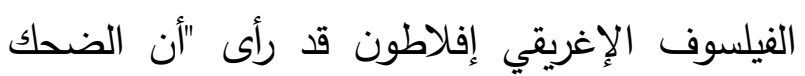

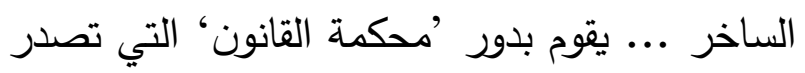

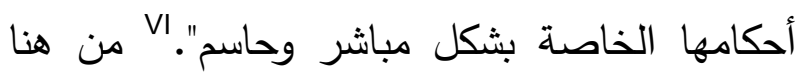

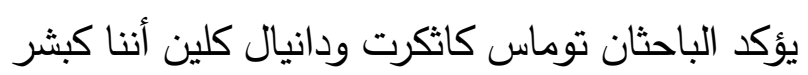

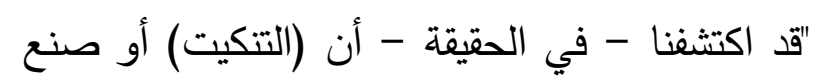
الطرائف هو إحدى الطرق الناعمة (البارعة) لاستخلاص الأفكار الفلسفية العامة".لVII ولذلك عدّ سيجموند فرويد الفكاهة "واحدة من أرقى الإنجازات النفسية للإنسان"، لأنها "تصدر عن آلية (ميكانيزم)

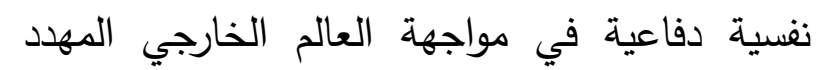
للذات، وتقوم هذه الآلية الدفاعية على أساس تحويل

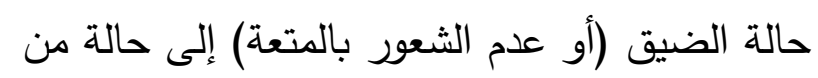

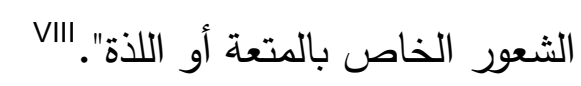

ع عبدالحميد، ص79 V

السابق، صن VI

VII Thomas Cathcart, Daniel Klein, Heidegger and a Hippo Walk Through Those Pearly Gates (New York: Viking Penguin, 2009) intorduction.
ويكون مضحوكاً عليه، لا مضحوكاً بسببه.

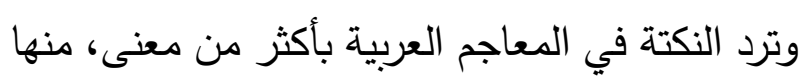

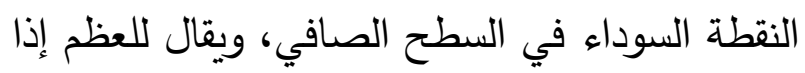

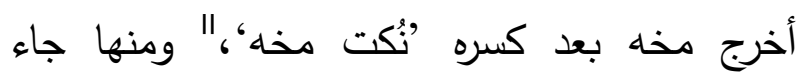
استخدام النكتة في التراث العربي أيضاً بمعنى جوهر لغره

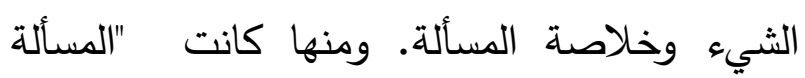
الاقيقة أخرجت بدقة وإمعان"، كما يستخلصها بوعلي

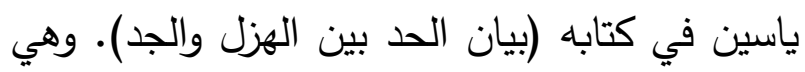

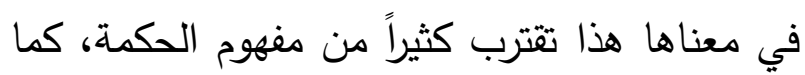
أن ياسين يورد المعاني الأخرى التي تقربها من مفهوم

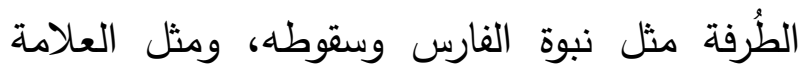
الخفية، كذلك تشير 'النكتة' أحياناً إلى الجملة اللطيفة التي تؤثر في النفس."' ويرى عباس السوسوة أن بديع الزمان الههذاني الذي عاش في القرن الرابع الهجري

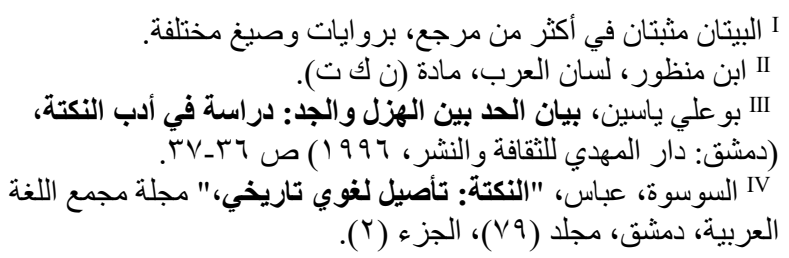


بخصوص مسألة استعصى على الذات الإنسانية

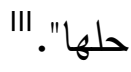

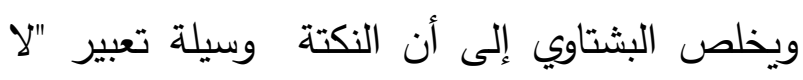
يمكن التحكم في مصدر صناعتها، ولا ضبط إيقاعها ولا حتى إيقاف رواجها كتعبير يُشكّل في حقيقته عملاً

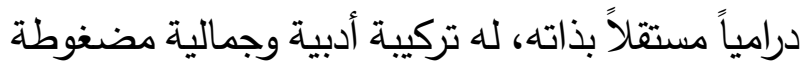
ومكثةة، تعمل على إفراز مشاعر ومواقف وآراء سلسلة IV وواعية".

وفي مقال للباحث الأكاديمي فالح العجمي عن (النكتة: تقويمها ووظائفها) أشار فيه إلى أن دافع المقال كان مناقشةً دارت في مجموعة (واتس آب) حول دور النكتة في المجتمعات العربية. ونقل العجمي قلق بعض الششاركين في النقاش من أن تكون النكتة

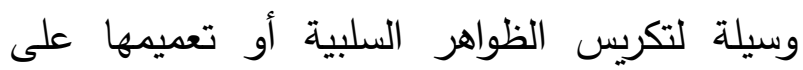

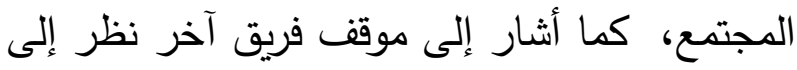
الجانب التتفيسي الذي يساعد على تخفيف الاحتقان

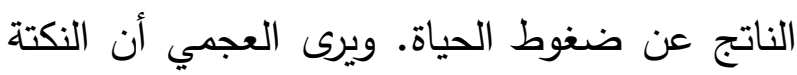

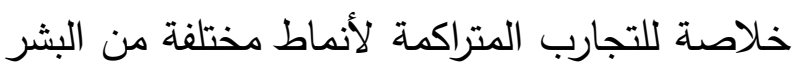

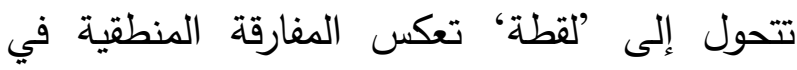
الموقف، لذلك تعد النكتة من أدوات النقد الفنية البارعة - والنلاذعة أحياناً- في التأثير على السلوك البشري. ويختم العجمي مقاله بتساؤل مهم له دلالته في سياق هذا البحث. يقول العجمي: "لكن ما مصيرها [أي النكت] بعد تغير وسائل نقلها؟ أي بعد تحولها من أداة

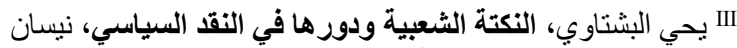

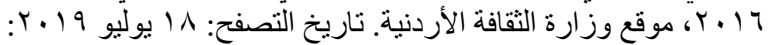
http://www.ich.gov.jo/sites/default/files/p2_1.pdf
لعل ذلك هو ما دفع فرويد لأن يخصص جزءاً من

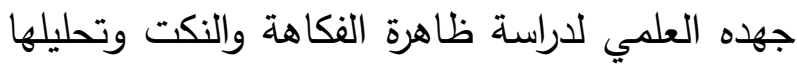

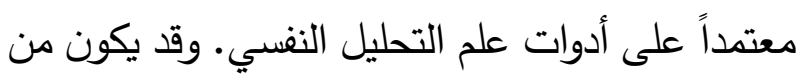

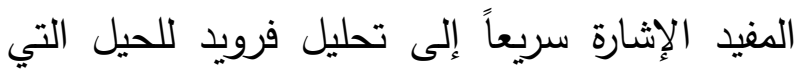

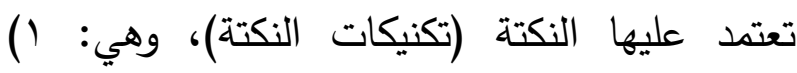
التكثيف الذي يتم إما بتركيب كلمات وعبارة معينة، أو

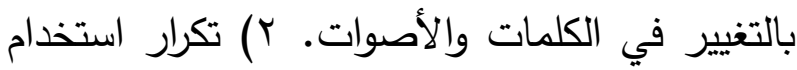

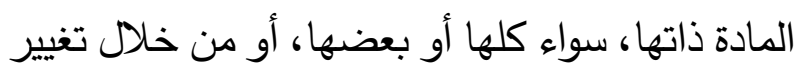
ترتيبها. أو من خلال استخدام دلالات مختلفة لكلمات معينة، أو معانٍ مزدوجة أو مجان مازية للكلمات والعبارات، أو عن طريق التلاعب بالكلمات. كل هذه هذونه آونه

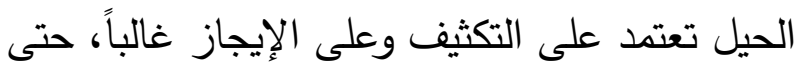
أصبحتا (أي التكثيف والإيجاز) أهم سمات النكتة. ويلخص عبدالحميد شاكر وظائف النكتة في عدة الهمات نقاط من أهمها: "تحقيق التواصل أو التفاعل الاجتماعي وتجديده"، و"تعزيز التماسك الاجتماعي"،

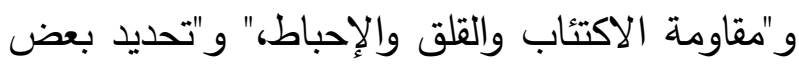
أنماط السلوك الاجتماعي المقبولة وغير المقبولة"، بالإضافة إلى "التخفيف من وطأة بعض الاجيماعي القيود الاجتماعية، والتعبير عن الاتجاهات العامة نحو لفالف السلطة"، سياسية كانت أو دينية أو غير ذلك." من هنا يرى يحي البشتاوي، في بحث له بعنوان (النكتة

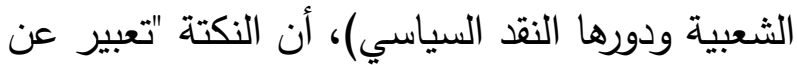
رغبة وتنفيس عن شعور مكبوت وتفريغ انفعالي 
ولصعوبة حصر النكت في كل هذه المواقع، فإن عينة الدراسة ستكون محصورة في عدد من النكت التي يتم تدويرها في تطبيق (الواتس آب)، لأنه - وفقاً لموقع

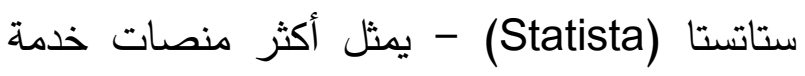
التراسل شهرة واستخداماً."' كما أن النماذج المأخوذة أنسات منه يمكن أن تشكل تصوراً شاملاً للظاهرة المطروحة أنها

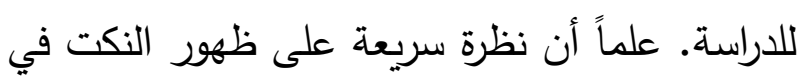
التطبيقات والمنصات المختلفة تكثف عن عدم وجود اختلاف كبير في طبيعة الظاهرة أو طريقة صياغتها، وقد يُحصر الاختلاف في الإمكانات والميزات التي يتيحها كل تطبيق على حدة. لا بد من الذكر أن ظاهرة النكت كانت موجودة، ولعلها كانت متداولة على نطاقات معينة؛ في المجالس، وفي المواقع الإكترونية ومجموعات البريد الإكتروني، لكن

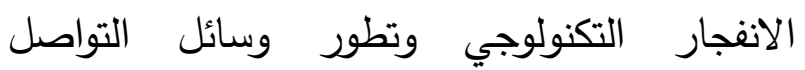
الاجتماعي، وظهور منصات الإعلام الجديد وتكاثرها أسهم بوضوح في انتشار هذه النكت وتوسيع دائرة متلقيها وموجهيها. وهذا يقود إلى التنكير في المحفزات التي كانت خلف وهن انبثاق الظاهرة على السطح؛ فرغم أن فئ نكت الحكيم

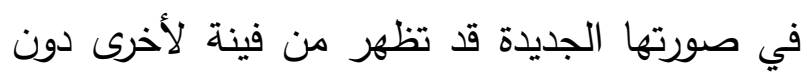

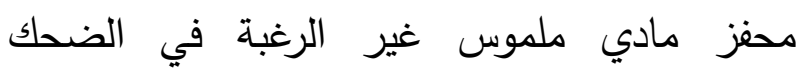
والإضحاك، إلا أن الأحداث والظروف تمثل محفزاً مهماً في الغالب لظهور هذه النكت وإعادة تدويرها Statista: the Statistics Portal, date of access 22 July 2019: <https://www.statista.com/statistics/258749/mostpopular-global-mobile-messenger-apps/>.
مباشرة (وجهاً لوجه، وفي إطار الأصحاب أو الثلة

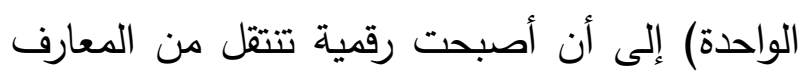

إلى غيرهم في سرعة كبيرة؟". ؛ - نكت الحكيم والإعلام الجديد

يبدو تساؤل العجمي في محله، فنكت الحكيم ـالتي

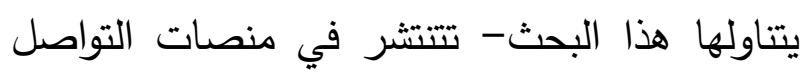
الاجتماعي والإعلام الجديد مثل الفيس بك وتويتر والواتس آب وغيرها، وتتداولها الحسابات (بشراهة) في هذه المنصات. ما حدا بالبشتاوي إلى أن يعد وسائل

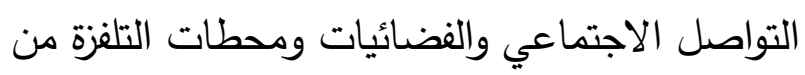
أهم عوامل انتثار هذه النكت واتساع دائرة تأثيرها." توفر المنصات الحديثة للإعلام الجديد ميزتين

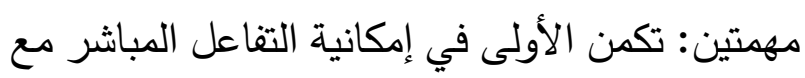

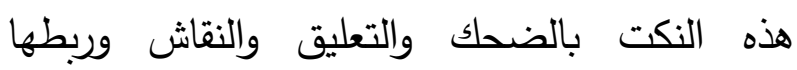
بالسياقات الاجتماعية أو الاقصادية أو السياسية

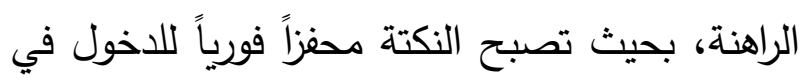
نقاش حول القضايا المختلفة. أما الميزة الأخرى التي لتي توفرها تطبيقات الإعلام الجديد فهي مساهمتها في

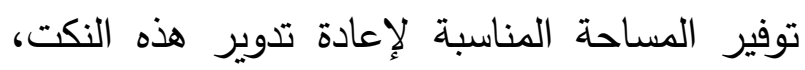

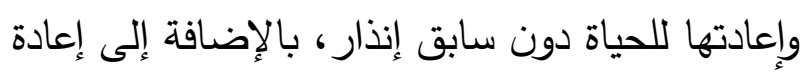

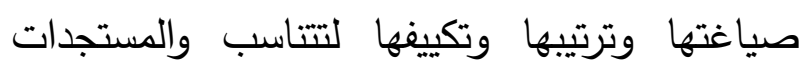
دوماً، حتى تبدو حديثة لم تصنع إلا لهذا الظرف أو وتك

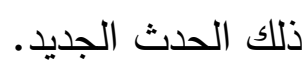

I فالح العجمي، النكتة.. تقويمها ووظائفها، صحيفة اليوم الإلكرونية،

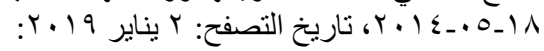
<http://www.alyaum.com/articles/931076/>.

البشتاوي، صـا II 
قال حكيم: السدكة التي تغلق فهها لن بصطادها أحد.

قال أحد الحضور: و إذا صادوها بثبك? قال الحكيم: من أين الأخج قال : من السعودية.

قال الحكيم: أنت من اللحي يداومون ساعة؟؟" بالطريقة نفسها في النكتة السابقة، ينتهي الحوار بين الحكيم وأحد الحضور بسؤال ساخر يوجهه الحكيم للحاضر المتذاكي، وهو بالأحرى سؤال إنكاري (استهجاني) يقصد به الجمهور أحد وزراء الخدمة المدنية في المملكة، إثر تعليق لله في برنامج تلفزيوني شهير قال فيه 'إن إنتاجية الموظف السعودي لا تزيد عن ساعة واحدة في اليوم'. تسبب هذا التصريح في حالة من الانفجار في الساحة المحلية السعودية، إذ اشتعل الجدل حول تصريح الوزير ودقة ما ورد فيه، وكفاءة الوزير لشغل منصبه الحساس. فأصبح التصريح حديثَ الصحافة والإعلام، وظهرت المقالات الشاجبة والرسائل الغاضبة والمقاطع الرافضة والحملات الإلكترونية ضد الوزير وفحوى تصريحه. خصوصاً وأن اللقاء جاء متزامناً مع عدد من القرارات الحكومية الهادفة للترشيد بإلغاء عدد من الامتيازات والحقوق المادية للموظفين في القطاعات الحكومية،

في الناس)، أي: ما لي وللناس!؟. وقوله: شخالات لرمضان يعني به

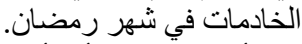

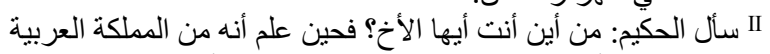

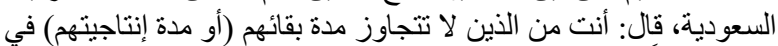

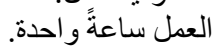

وانتشارها، بعد إعادة صياغتها لتتكيف مع استجد من

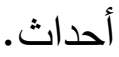
وقد يكون الظرف حدثاً اجتماعياً أو اقتصادياً أو رياضياً أو قراراً يحرك الرأي العام، ويستيره فتكون النكت فرصة للتعبير والتنفيس. مثل: أتحى حكيم إلسى رجل فقال لله: هل أدلك على ثلاث إن فعلتها نلت رضا الناس ؛ قال الرجل: وش دخلني في الناس فقال الحكيم : والله إنك صادق، طيب تعزف أحد يجيب شغالات لرمضان؟' يشير تساؤل الحكيم في آخر النكتة إلى ظرف اجتماعي موسمي، تحول إلى ما يشبه الظاهرة الاجتماعية، إذ تتصاعد حاجة العائلات في المملكة العربية السعودية لإيجاد مساعدة في الأعمال المنزلية (حيث يتكثف في الشهر نشاط إعداد الموائد الرمضانية التي تجتمع حولها الأسر مع رغبة في الانشغال بالعبادات)، فيكثر السؤال عن توفر الخادمات المؤقتات، وتبدأ حركة تشبه نشاط السوق السوداء الذي يبرز فيه الوساطات والمزايدات. وهذه نكتة أخرى أعيدت صياغتها بطريقة ساخرة لتشير إلى مقولة وزير من الوزراء في السعودية في لقاء تلفزيوني، مقولةٍ تسببت في إحداث ضجة كبيرة تحولت إلى قضية رأي عام. تقول النكتة:

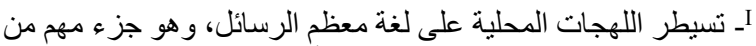

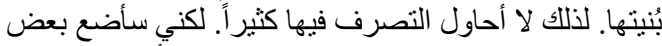

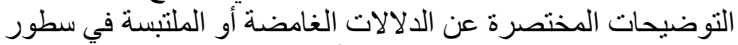

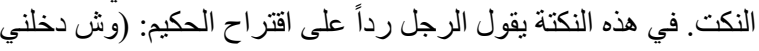


(حافز)، الذي سرعان ما يوقف عطاءه عن أولئك الذين لم يبادروا بتحديث بياناتهم في سجلات البرنامج. ه- صور الحكيم في خطاب النكتة تشير عينة الدراسة إلى أن الحكيم يظهر في عدة صور فئر فئه مختلفة، فهناك صورة الحكيم المعتادة، فهو الفصيح البليغ عميق الخبرة والتجربة: سئل حكيم: من أسعدُ الناس؟ قال: من أسعََ الناس.

سألوا حكيهاً: أي انواع الموسيقى هو الحرام؟ فأجاب: صوت الملاعق في صحون الأغنياء عندما ترن في آذان الفقراء.

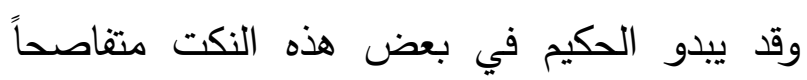
متفذلكاً. تؤدي به محاولة الفذلكة والتذاكي إلى عواقب وخيمة:

سأل غلام حكيًا: ماهي الثجاعه؟؟

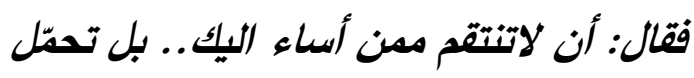
وتصبّر.

فبصق الغلام في وجه الحكيم لينتبره.

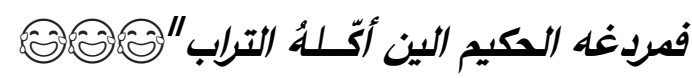
فقال الغلام: واللهه إنسي داري إنك كنوب النه

طلب أحل الحكماء من ملخنين ان

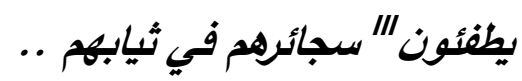

ـ أي أن الحكيم ضربه ضرباً مبرحاً، حتى تلطخ جسده بالتراب. III _ الصحيح نحوياً بطبيعة الحال: (يطفئو ا).
ما أدى إلى حالة عامة من القلق والإحباط في المجتمع السعودي. إل إن وتستغل بعض (النكت) الحدث الاجتماعي بطريقة

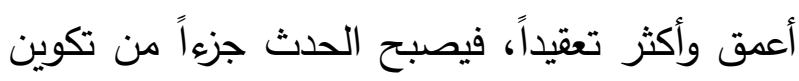
الحكمة شكلاً ومضموناً، كما يلاحظ في هذا المثال: قال حكيم سعودي يا بنسي..كن في حياتك مثل ساهر وانتهز كل فرصة والتثطها وإلا فإن حياتك ستكون مثل حافز تنساك إن لث تحدثها توظف النكتة نظاميْن حكومييْن من برنامجين مختلفين

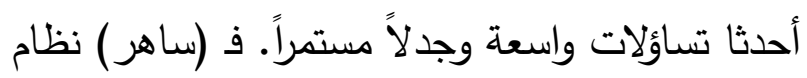
مروري آلي يتصيد المخالفات المرورية لسائقي المركبات في المملكة، ويحرر على إثرها غرامات مالية عليهم، أما (حافز) فهو برنامج دعم حكومي المكي

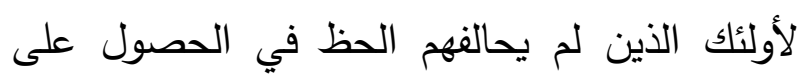
وظائف أو على دخل مادي ثابت. وتستثيد

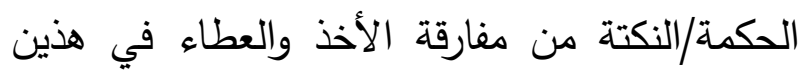
البرنامجين لتجعلهما جوهزَ الرسالة التي يريد (الحكيم

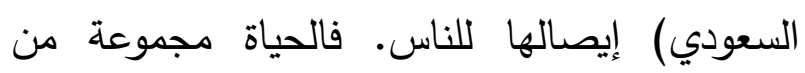
الفرص التي لا ينبغي تفويتها، والنموذج هنا هو برنامج

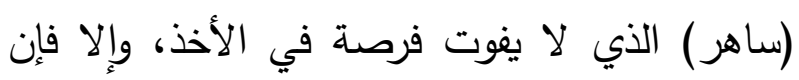

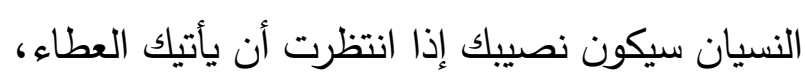

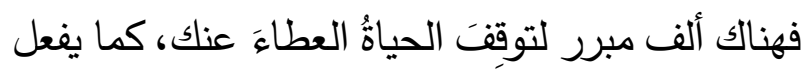

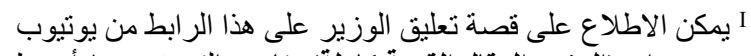

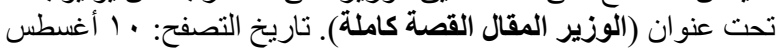
$<: Y \cdot 19$ https://www.youtube.com/watch?v=109uPx5aNxU> 


$$
\begin{aligned}
& \text { وارمه بالمورد !!! } \\
& \text { مع المزهربية طبعًا } \\
& \text { والطاولة إذا (كنت) تثدر . } \\
& \text { مساء التسامح' }
\end{aligned}
$$

وقد يكون الحكيم أحد مشاهير اللحظة في وسائل الإعلام الجديد، مثل شخصية (العم معيض)، الذي أصبح أحد المشاهير المختلف حولهم، بعد تسرّبٍ مقطع فيديو لله وهو يضرب أبناءه بالعصا، وهي قصة تحولت إلى حديث الرأي العام وتدخلت فيها أطراف رسمية وغير رسمية كثيرة. وقد وُظّفتْ شخصية العم معيض بعد تحولها إلى نموذج يفضي إلى صفات معينة في عدد من الرسائل والنكت الشعبية: يقول شكسبير:

أحضان الأنثى ودفء جسدها يزبل هدوم اللنيا وضغوطها ... وقال أبيضاً: الرجل الأي بعامل المرأة كملكة دليل علحى أنها تربحى على بإ ملكة أخرى. وهنا دخل 'معيض' بفلسفة مغايرة. وقال: المرأة كالكهرباء.

إذا أحسنت استخد/مها أضاءت لك حياتك بإلنور

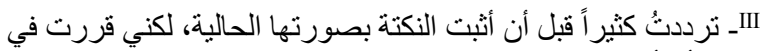

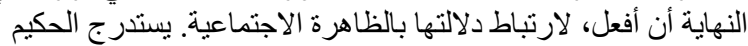

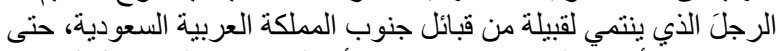

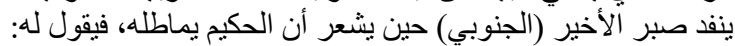

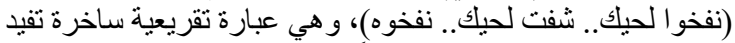

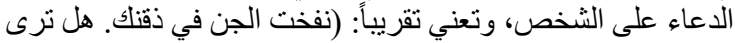
ذقنك!! نفوه).

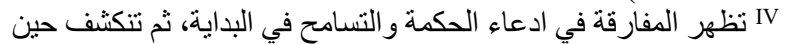

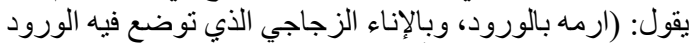

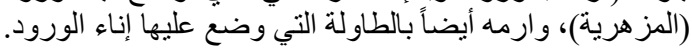

قال أحدهم : وهل نحن مجانين !! حتى نحق ثيابنا فرد الحكيم: هل ثيابكم أغلحى من أرواحكم !! قال المدخّن: علحى شحم.. لا أطفّيها في خشمك.' فذهب الحكيم وهو بردد مقولية ابن مصلح الزهرانسي:

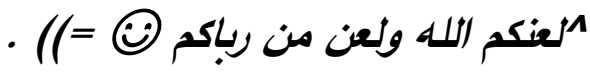

أحد الحكماء سأل جنوبيًا: هل الهواء الذي نخرجه من صدونيا حار أم بارد؟ قال الحكيم: أجل.. لماذا نتفخ أيلينا لندفئها عندما لاريا يكون الجو بارداً: استدرك الجنوبي.. ثم قال: لا .. حار قال الحكيم: إذن.. لماذ/ نتفخ كوب الشاي الحار لكي نقوم بتبربله؟ قال الجنوبي: نفخوا لحَيك .. شفت لحيَك؟ تفخووصوه وهنالك الحكيم الواقعي الذي يفكر ويتصرف مثل بقية البشر : - 20 - n إذا رماك أحد بكلام جارح فكن حكيها

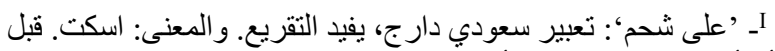
أن أطفئ السيجارة داخل أنفلك.

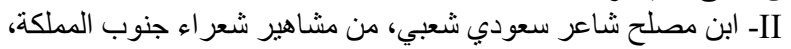

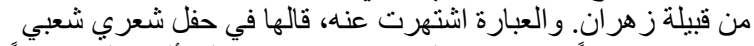

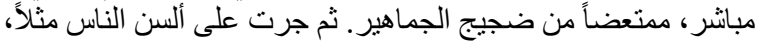

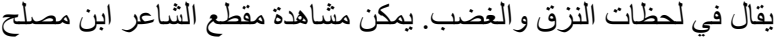

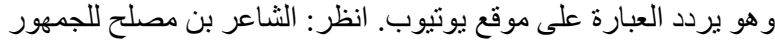

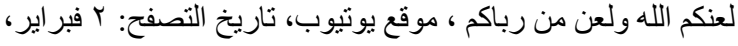
$: r \cdot r$. $<$ https://www.youtube.com/watch?v=KRqoH8e_lsc $>$. 


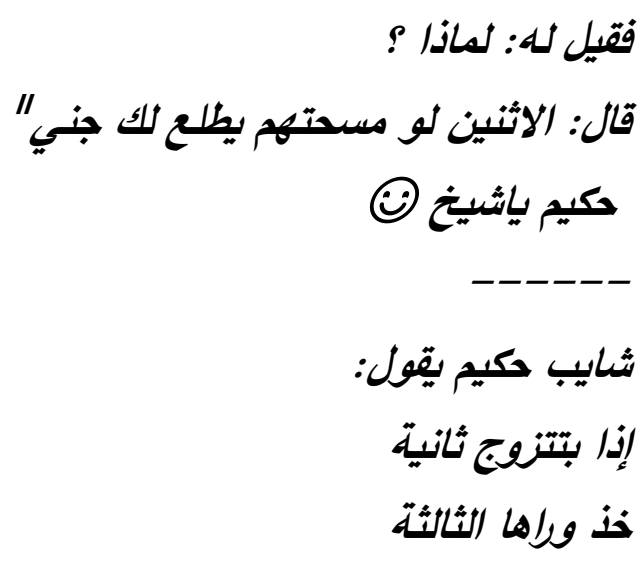

عشان تبرّّ قلب الأولِى و تقرص الثانية وتخوّف الثالثة من اليرابعه

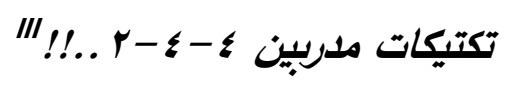
צ- بنية السرد وهيكل النكتة

يمكن القول إن معظم النكت التي تثكل عينة الدراسة

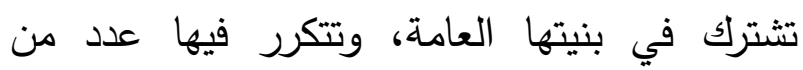
المظاهر النصية والسمات الأسلوبية، لذلك يمكن فئكرن

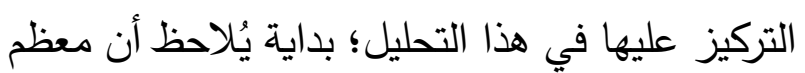
النكت تأتي على شكل قصة قصيرة، تتضمن حواراً يكون الحكيم طرفاً فيه، وتحضر فيه الأسئلة، كما تأنين تحضر النهاية غير المتوقعة، والجملة الختامية التي تشكل ما يشبه (القفلة النهائية للنكتة). وسيركز هذا

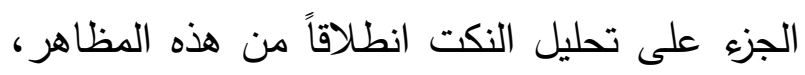
لتوضيح العلاقة بين هيكل النكت وسماتها النصية،

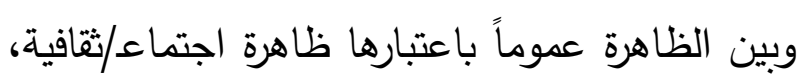
بقدر ما هي ظاهرة لغوية.

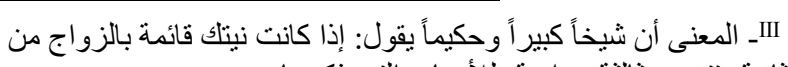
ثانية، فنزوج ثالثة ور ابعة، للأسباب التي ذكر ها.
وإذا أسأت استخد/مها نفضتك .. ونفضت أم اللحي جابتك!! أعتقد كلام معيض مقنع أكثر من شكسبير. حكيم بإ معيض..!!

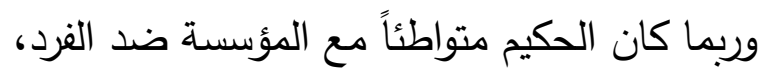

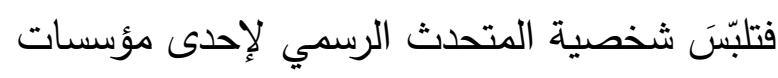

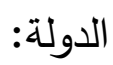
اشتكى رجل مهووم إلىى حكيم عدم امتلاكه منزلًا. فقال لهه الحكيم: سوف أسالك سؤلين علين فاصدقني القول : هل جئت إلى هذه الدنيا ومعك لهك منزل؟ قال الرجل: ل الو فقال الحكيم: وعندما ستترك الدنيا، هل ستأخذ معك لرك منزلك الحى الآخرة؟ فقال الرجل: لا

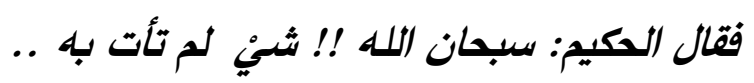

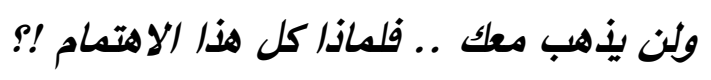

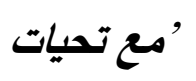
ونارة الإسكان .. قسم التوعيه الدينية، .

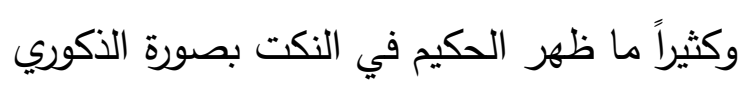

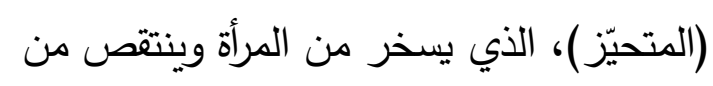
مظهرها ومن تفكيرها وعواطفها:

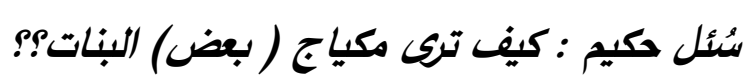
قال: أثباه ببصباح علاء الدين :كئ تركات

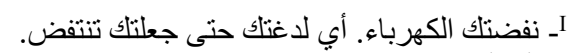

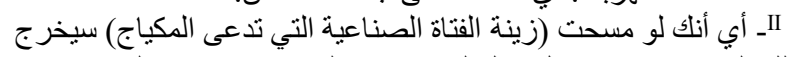

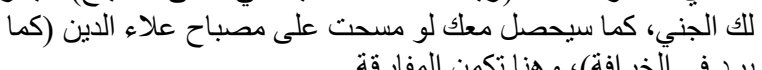


القصص استحضار لهذه الوظيفة، لكن في سياق مختلفٍ يسائل ذلك الدور التربوي، إذ تُظهر هذه النكت رفضاً لهذا التقليد (القصة التي تتنهي بعبرة وعظة). ويمكن قول ذلك على تقنية الحوار، وما فيها من استدراج للقارئ نحو النهاية التي تحمل الخلاصة (الأخلاقية والوعظية) . ويقوم الحوار في القصص بعدة التصائ وظائف، منها " الكثف عن مواقف الثخصيات بعضها من بعض"، ويرى إبراهيم محمود خليل أن منان

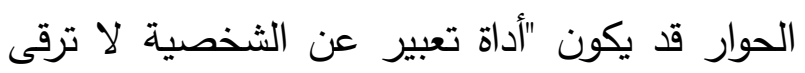

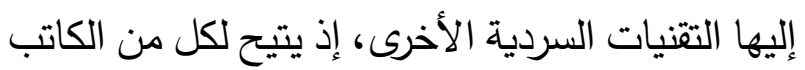

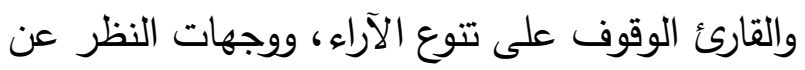

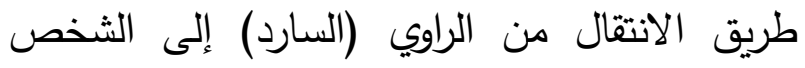

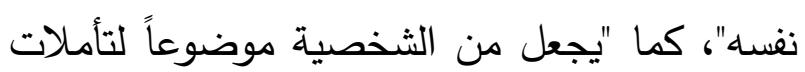
القارئ، ينظر إليها نظر جديدة تختلف عن نظرته إليها

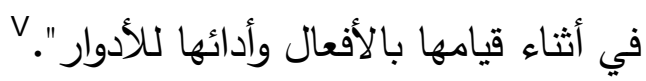

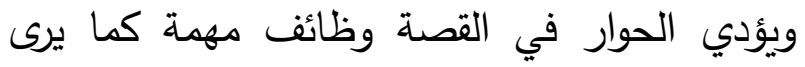

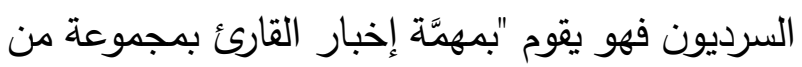

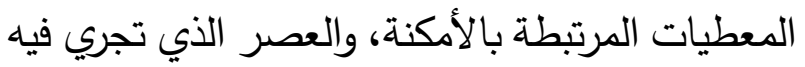

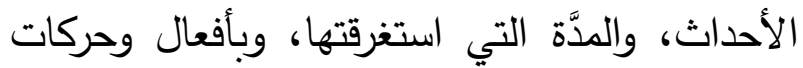

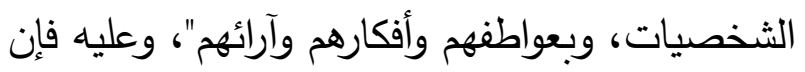

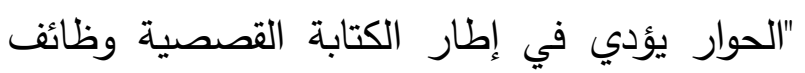
محددة؛ منها: وظيفة تفسيرية إخبارية تجعل الأقوال

السملالي، فن الرواية، شبكة الألوكة الأدبية و اللغوية، 17 ديسمبر

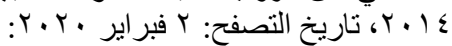
<https://www.alukah.net/literature_language/0/79895/>

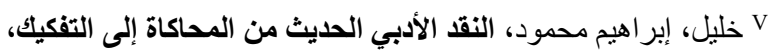

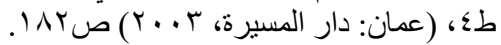

يميز الناقد تيد كوهين في كتابه (النكت: أفكار فلسفية حول قضايا تتكيتية) بين نوعين من النكت: النكت

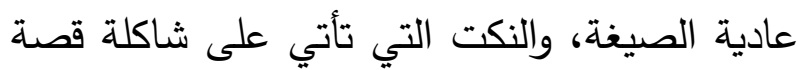
قصيرة.' وغالبية النكت التي شكلت عينة هذه الدراسة

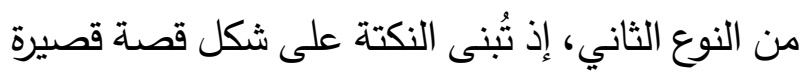

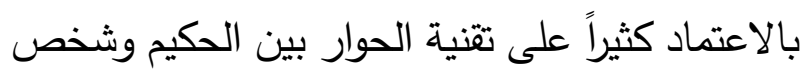

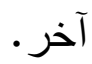
ولطالما ارتبطت القصة بالوظيفة التربوية، فالتعلّم والاعتبار والاتعاظ كلها من الوظائف التقليدية التي لتئه يؤديها السرد، ويذكر عبدالله إبراهيم أن الحيز الدلالي الدي الذي أسسه القرآن لمفهوم القص يتلخص في في "الخبر المقيد بالدقة والصواب والحق واليقين والاعتبار والتدبر

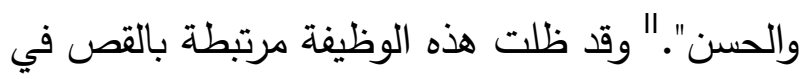
الثقافة العربية بعد ذلك، "لتحقيق أغراض وعظية وأخلاقية ثابتة... فيكون مجلس القصصبة بعد دل.. مجلساً

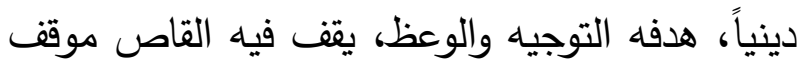
الواعظ الديني... ثم ينحو منحى تعليمياً في بيان

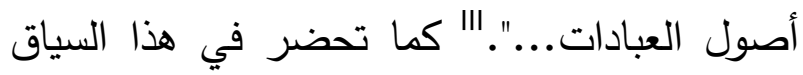

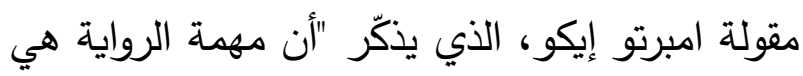

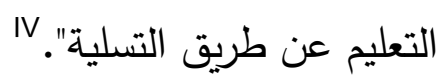
تمثل القصةُ إحدى الصيخ التي خرج بها لتهايه العقل البشري

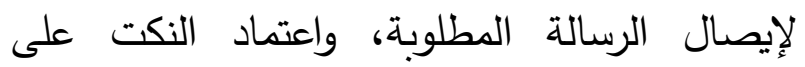

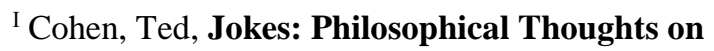
Joking Matters, (Chicago: University of Chicago Press, 1999) 1.

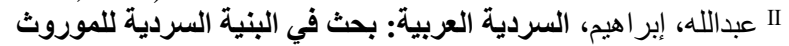

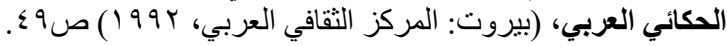

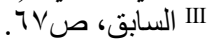

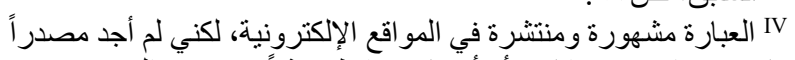

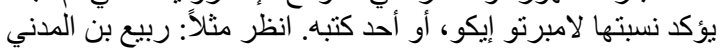


للسخرية. كما يقود الحوار في النكت إلى أبعاد غير مرئية، أو مسكوت عنها، مثل نظرة الإنسان العادي نحو تقمّص الحكيمٍ دورَ العارف المطلق بطبيعة الحياة وأسرارها. يؤدي الحوار دور الخلفية الصوتية للقصة، لكنها -كما توحي النكت- خلفية ثابتة ومملة، غير ملونة كذلك، في عصر الألوان والموسيقى غير المحدودة، وعصر تعدد الأصوات والمنابر، وتشظي الخطابات، وصعود الجماهير • لكن الحوار، الذي يبدأ عادياً وروتينياً، ينقلب إلى ما وهات يشبه الكمين اللغوي، الذي يكون الحكيم فيه إما ضحية لئية له (كما حصل مع حكيم السمكة، وحكيم رضا الناس)، أو متواطئاً في صنع الكمين (كما هو الحال مع حكيم الفتى، وحكيم الفيمتو في المثالين السابقين). يكون الكمين بالانقلاب على سير الحدث في القصة؛

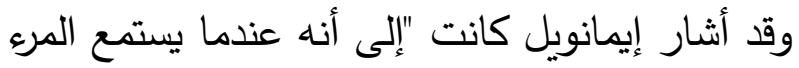
إلى نكتة فإنه ينمي بداخله حالة من التوقع تتعلق التقاتل بالانتظار إلى النقطة التي سيتغير الأمر عندها...

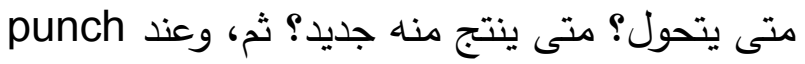

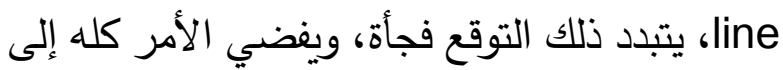

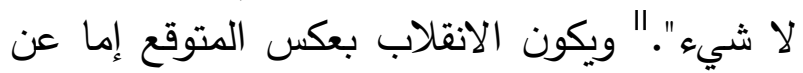

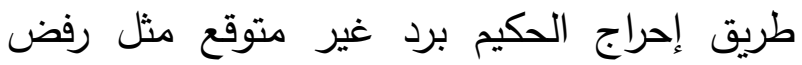

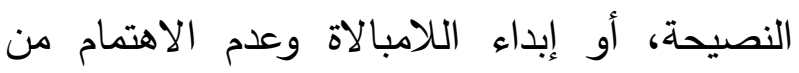

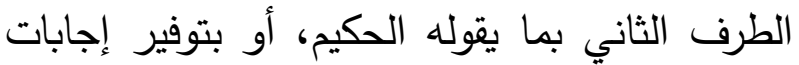

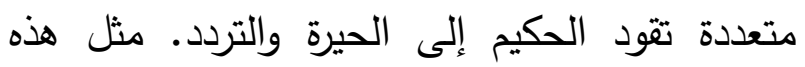
الإجابات تجعل الحكيم يكتشف أن الزمن قد تغير التردئ

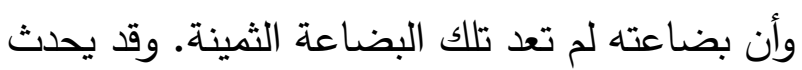
الانقلاب بناء على رد فعل الحكيم العادي والساخر

</http://www.alukah.net/literature_language/0/110556>. 91 (بدالحميد، ص II
وسيلةً لعرض عناصر الحبكة، ورسم مجرى الأحداث. ووظيفة درامية وذلك حين يعمل تدخل أحد المتحاورين على تحريك الأحداث وإحداث الصراع. ووظيفة وصفية وذلك حين يعكس الحوار سمات الثخصية النفسية وطريقتها في التعبير عن مواقفها وأحاسيسها". ويمكن ملاحظة كيف يقدم الحوار هذه الوظائف للقصة عولئ

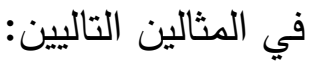
فتحى سأل حكيم: لماذا أعشدق فتاة حتى الجنون

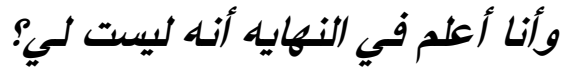
فقال : لإنك خروووووووفف !!

وسأل أحد حكيم قال: ما السر في بثاثتة وجهك

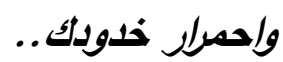
قال : أثرب فيمتو هون يبدأ الحوار - كما هو مُلاحظ في النكتتين السابقتين - بطريقة تقليدية؛ حيث يبادر الفتى في النكتة الأولى،

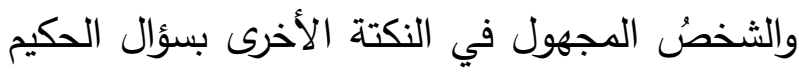
سؤالين يبعثان على التأمل، ويوحيان ببحث السائليْن عن إجابتين عميقتين تتجاوزان ظاهر اللفظ وسطحية المعنى. وهما سؤالان يليقان بالحكيم وفقاً لصورته النمطية في الذهنية الجمعية. غير أن الحوار في النكت يكثف عن جوانب جديدة في الموقف الوعظي، أو في شخصية الحكيم؛ فنظهر بشريته المبتذلة، ويظهر م-ثله مثل إنسان الثارع إن صح التعبير - سريحَ الغضب، أو أحمقَ مثاراً I هر امة، حميد، النص السردي، موقع الألوكة الإلكرتوني، تاريخ

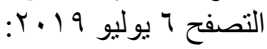


قالت الأفعى لمنارع حكيم : أنس

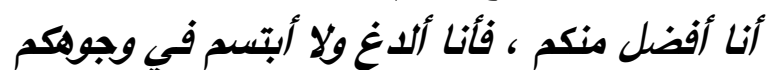

كما تفعلون ببعضكم مارل

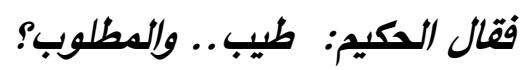
قالت: لا .. بس أقول لك. ..!!

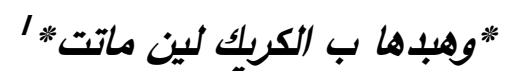

قابل حكيُّ رجلًَ فقال لهه:

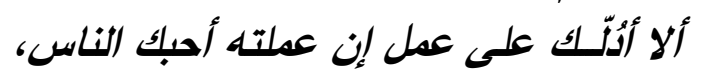
وأحاط بك الأصدقاء وتودّدَ إليك الأعداء؟ فقال الرجل : "ل . . فطاح وجه الدكيم....

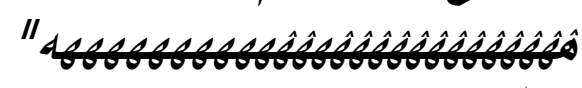
تُوظَّتَّ القصة، وينبثق الحوار داخلها، وتحضر

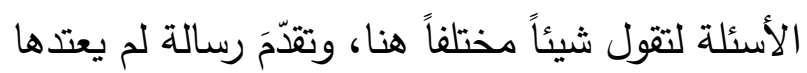
الذهن العربي، وكأن في الأمر مساءلةً للطريقة التقليدية التي درج عليها الفكر العربي في اصطياد

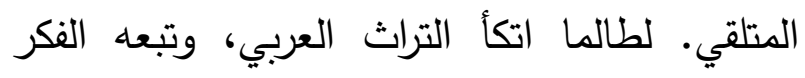
العربي الحديث، على الدور الكسول للمتلقي البسيط، و اللعبٍ على أفق المتوقع منه؛ يُتوقع من هذا المتلقي - كما يصوّره الوعي العربي- أن يكون المستمِحَ

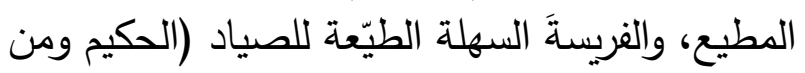

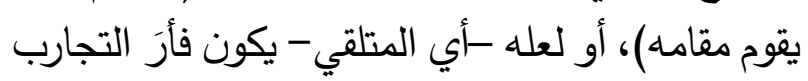

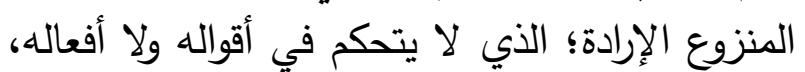

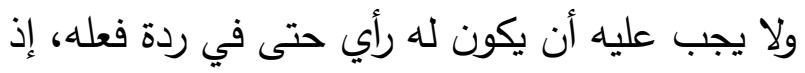
يسيطر عليها هذا الحكيم المتسلط على حواسه وإرادته.

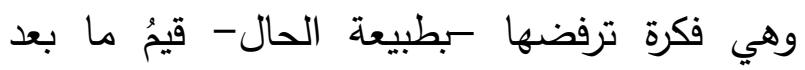
الحداثة، التي تقود الجماهير إلى الصف تلف الأمامي،

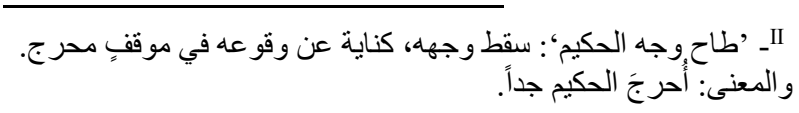

والمبتذل (مثل 'لأنك خروف' و 'أشرب فيمتو')، على أسئلة السائليْن الراغبينن في الاستزادة من معين حكمته.

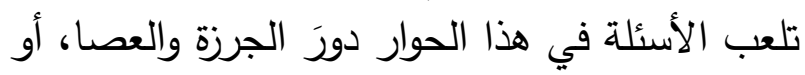

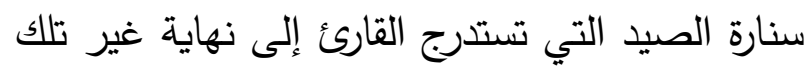

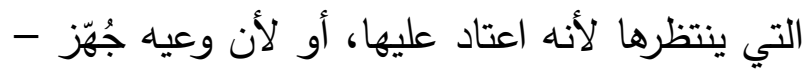
عبر تاريخ طويل من التلقين- لتكون هي إجابته الوحيدة. ولُعبةُ الأسئلة تقنية أخرى معتمدة في هذه

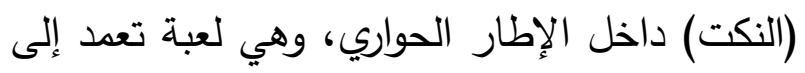
التشويق، واصطياد المتلقي بذكاء، سواءٌ كان السؤال

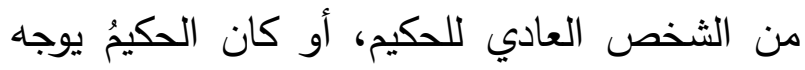
الأسئلة بنفسه، في محاولته لجذب اهتمام الطرف

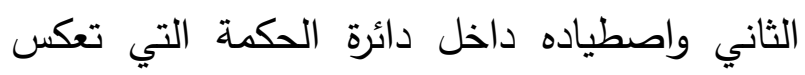
جوهر التجربة البشرية. وعادة ما تخُتتم هذه النكت بجملة ختامية، وهي تأتي لتئي

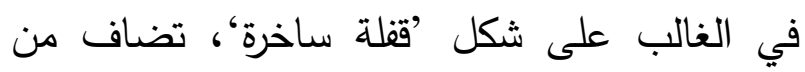
السارد (سواء كان طرفاً في الحوار أو سارداً خارجياً). وتكون هذه القفلة عبارةً وصفية سريعة تظهر حال فرال الحكيم بعد وقوعه في الكمين أو مشاركته في الإيقاع

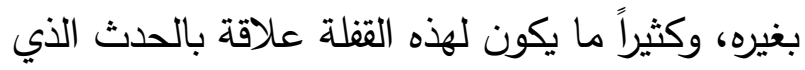
طوعت من أجله النكتة: جاء رجل حكيم لرجل بـخِّن في المطار كان بنظر لطائرة من خلف الزجاء لهاج

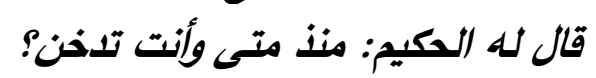
قار: منت ثلاثين عاماً.

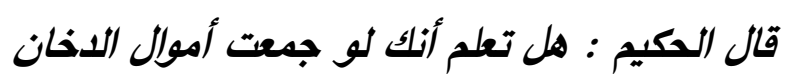
لثلاثين عام لاستطعت شعاء هذه الطائرة. قال المدخن: هذه طائرتي.. قال الحكيم : عطنحي سيجاره ..

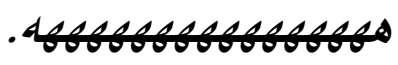

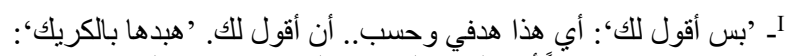
ضربها بشدة، مستخدماً أداة الحفر الحديدية التي تسمى (كريك). 
وقد عبّر عن هذا الرأي أحمد أمين -صراحةً في كتابه (فيض الخاطر ) حين رأى أن العامية منتشرة في

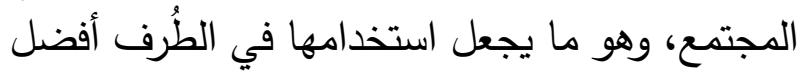
و 'ألطف، ، ويبث فيها روح الحياة والقبول؛ يقول: "فإذا حولت النكتة العامية إلى لغة فصحى سَّجتْ، كما وله تتبه إلى ذلك الجاحظ|| دن قبل..... والناس عادة لغة فئه يتقبلون ما يكتب باللغة الشعبية قبولاً حسناً؛ لأن النبوغ فيها أبرع، وهي لهم أنسب". IV وفي نكت الحكيم تأتي لهاتي

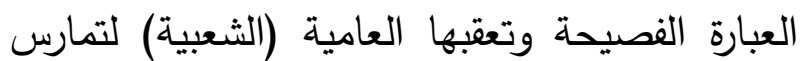
ازدواجيةٌ اللغة لعبَتها في ذهن المتلقي؛ يسأل الحكيم بعض الثبان المدخنين: هل ثيابكم أغلى من أرواحكم !! فيرد أحدهم: على شحم.. لا أطفّيها في خشمك. (وهذا تعبير شعبي يشير إلى غضب هذا الشاب من

$$
\text { تفاصح الحكيم). }
$$

وفي نكتة أخرى يبادر الحكيم رجلاً بالسؤال: هل أعلمك ثلاثة أشياء إذا فعلتها نلت رضا الناس!؟ لئ فيأتي رد الرجل مفاجئاً: لا .. علمني متى ينزل الراتب وفكّنا

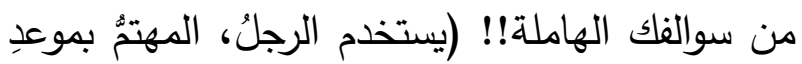
صرفب الراتب الثهري أكثر من حِكم الحكيم، عبارةً 'سوالفك الهاملة، ، وهي عبارة شعبية تعني الأحاديث

$$
\text { غير المفيدة وغير الهادفة). }
$$

وحين يتمادى حكيمٌ ما في استدراج محدثيه بالأسئلة

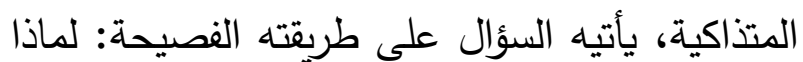

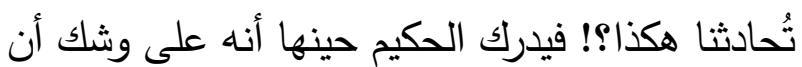

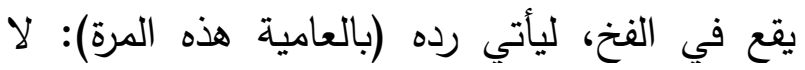
والله... تعرف حكيم ولازم أتبهلل (أو أستهبل، بمعنى:

$$
\text { أتذاكى وأتقذلك). }
$$

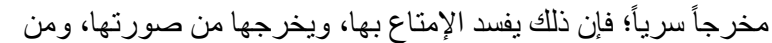

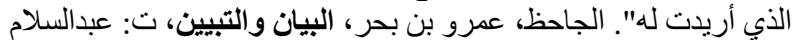

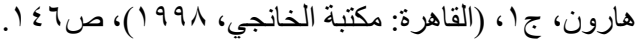

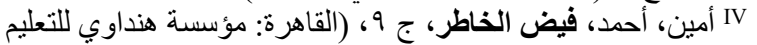

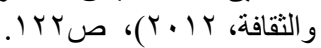

وتتراجع فيها سلطة النخب، حيث الإعلام والصورة تتيحان للجميع المشاركة؛ بحيث يمكن لأي فرد أن

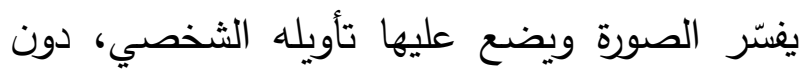
إملاءات مسبقة؛ وهذا ما "أطلق إمكانيات التأويل الحر، مثلما وسّّع دوائر الاستقبال وساوى بين الناس ماس في ذلك"، كما يقول عبدالله الغذامي. وهذا بدوره أسهم في تغيير اجتماعي واضح، حيث أصبح صوت الجمهور مسموعاً، وأصبح رأيه ذا قيمة، في الحيل الحكم على الظواهر والقضايا، فيما تراجع صوت النخبة، وانحسر دورها في التأثير والتأويل والوصاية؛ هذا لا لانح يعني أن النخب قد اختفت ولم يعد لها دور أو وجود، لكنها -كما يؤكد الغذامي - "فقدت دورها في القيادة والوصاية وتلاشت تبعا لذلك رمزيتها التقليدية التي

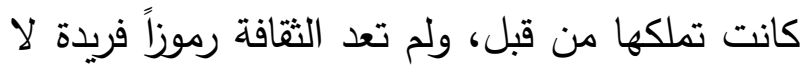

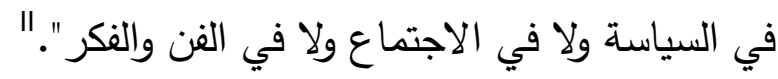
V- سلطة اللغة وعامية الفصيح بعيداً عن محاولة التفاصح وتكلف البلاغة التي تسم بعض هذه النكت، فإن أهم المظاهر اللغوية التي تصبغها هي الخلط بين الفصيح والعامي، وهو تكنيك أساسي لا يخلو من دلالة؛ فالفصحى كانت وتظل رئل لطبقة النخبة الثقافية، وهي سمة من سماتهم، وإن كان العامة يقدّرون اللغة الفصحى باعتبارها لغة القرآن

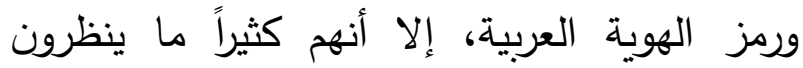
لمتحدثيها من النخبة بنظرة أقل تقديراً، حتى تحوّل الحديثُ بالفصحى عيباً أو نقطة للسخرية، يشار إلى مستخدمها بالتقعّر والتكلّف في الحديث لإثبات اختلافه عن طبقة العامة في مجتمعه.

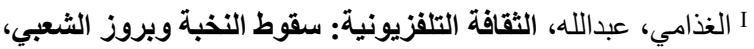

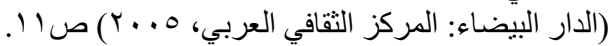
السابق. II

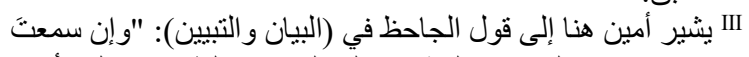

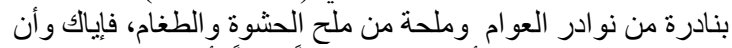
تستعمل فيها الإعراب، أو تتخير لها لفظاً حسناً، أو تجعل لهام الهن فن فياك 
(الخرفنة) جذراً معجمياً متشظياً: (خروف، خرفن،

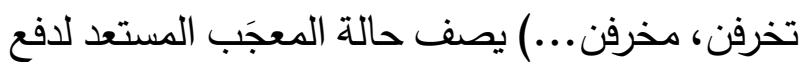
كل ما لديه من أجل الحصول على رضى رضا المعجَب بها.

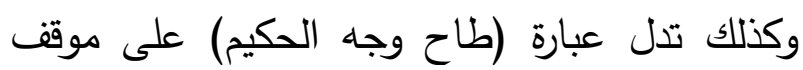

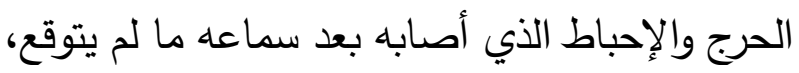

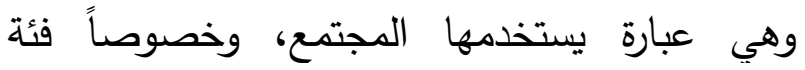
الثباب، كثيراً، فتكون عبارة (طاح وجهي)، أي أني أحُرجتُ فجأة حتى أُسقط في يدي ولم أحر جوابِاً، وهو

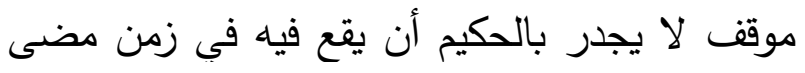
على ما يبدو. وهكذا تأتي العبارة العامية بجوار أختها لإنها

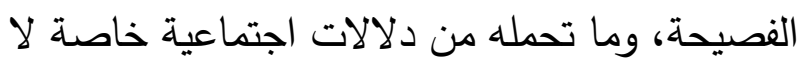

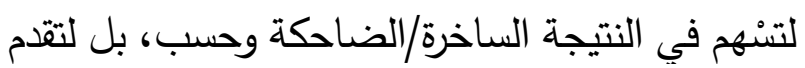
إضافتها للرسالة العامة، والخطاب الخفي الذي تحمله ظاهرة النكت الثعبية. ولا تكون اللفظة العامية رداً من الحكيم أو من محاوريه

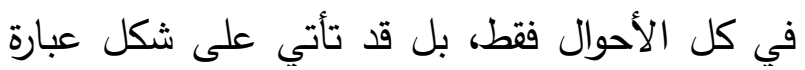

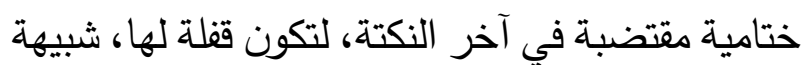

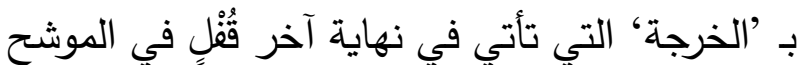

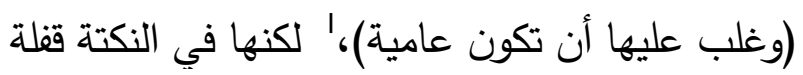

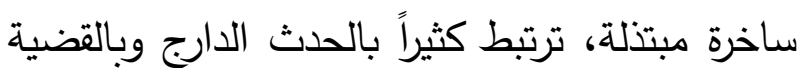

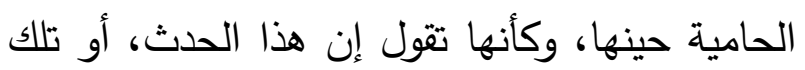

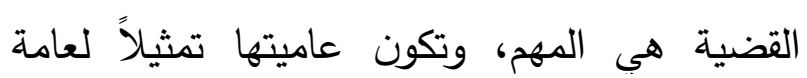
المجتمع (الذين يمثلون أكثرية الجماهير)، وهذا هو ما هائه يهم هذه الجماهير حقيقة، وليس حكمتك ومعرفتك وبلاغتلك وكل التراث والتقاليد التي صنعتلك حكيماً في ولين هذه الصورة.

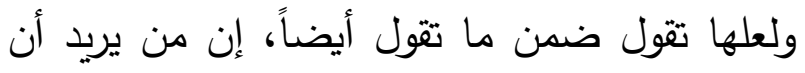

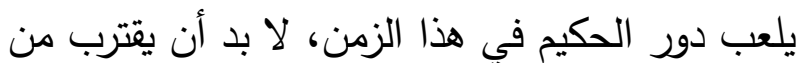

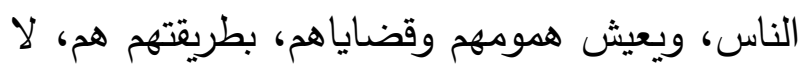

في هذا المثال الأخير ، يحرص الحكيم، في الحال التي يتلبّس فيها الدور التقليدي الجاد، على الفصحى وهو بحري يحاور محدثيه، لكن حين يأتي السؤالُ من أحد الذين الذين

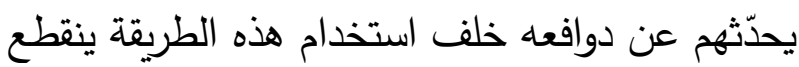

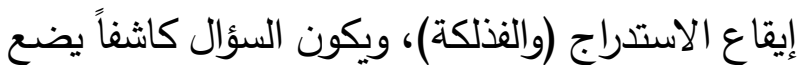

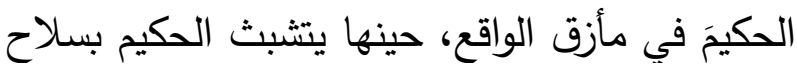
محثثيه من العامة، ويرد عليهج بلسانهم (العامي) رداً يشي بأن دوره يقف عند حدود هذه الألعاب اللغوية التانية والتفاصح ليس إلا، وتكون (البهللة) وظيفة الحكيم الذي لطالما شغل مناصب معرفية وفلسفية مقدسة. ولا بد من الوقوف عند هذه العبارات المحلية الصرفة

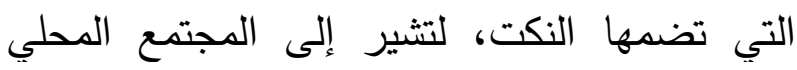

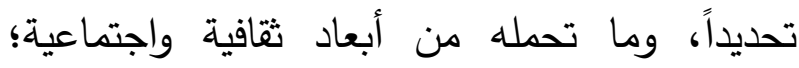

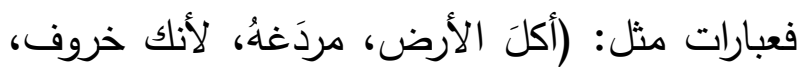
هبدَها بالكريك، طاح وجه الحكيم، وغيرها) مرتبطة الأنة

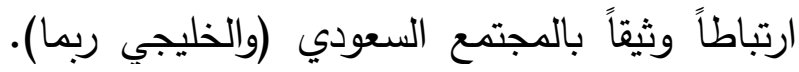
وغالباً ما تؤدي وظائف دلالية أبعالية أبعد من معناها

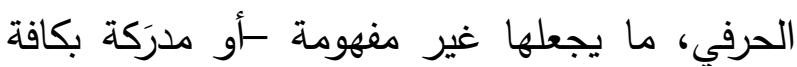

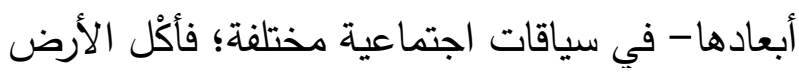

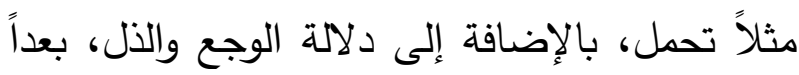

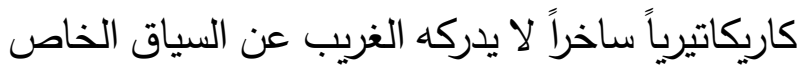

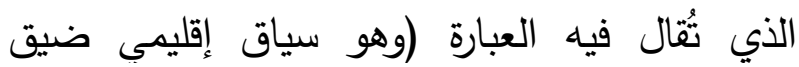

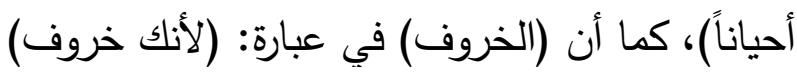

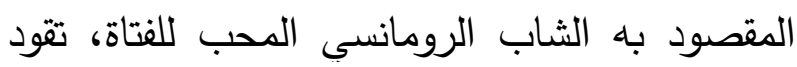

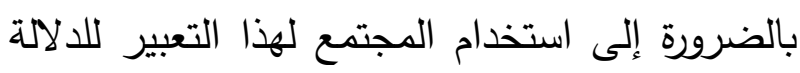

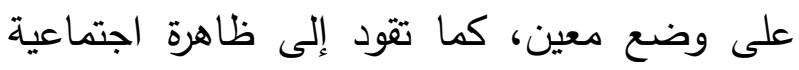

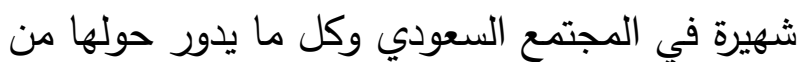

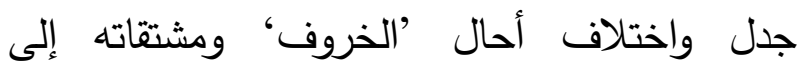
مصطلح اجتماعي بارز في المعجم المحلي، فأضحت ومثته الخت 
بأخرى، وممثلهم في هذا السياق هو 'الحكيم' الذي

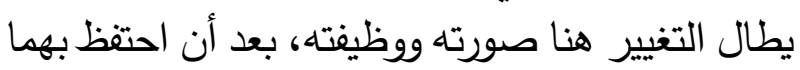
طويلاً في الوعي الجمعي. وهو تغيير يعني -كما أظهرت النكت وما تحمله من النها روح ساخرة- اهتزاز صورة النموذج، الذي يمثله الحكيم

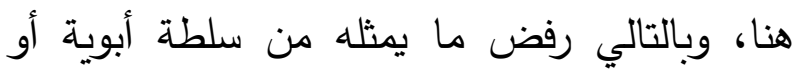

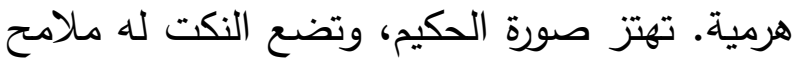

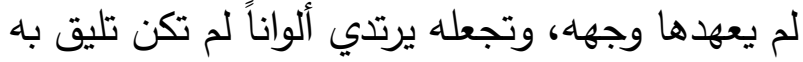

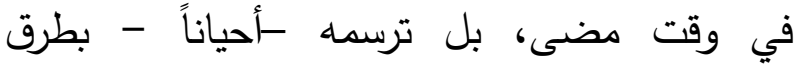
كاريكاتيرية، وتورطه في مواقف محرجة تحول فيها تفاصحه وتذاكيه إلى فخ، يجعله يبدو مهرّجاً بهلواني الطباع. كل هذا يقود إلى وضع سلطته تحت مجهر الثك، فتصبح موضحَ تساؤلِ المجتمع، واستتكارهم ربما. فهل يعني هذا أن الحكيم (بصورته التقليدية

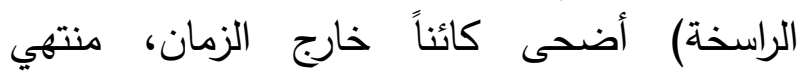
الصلاحية، لا وظيفة له في زمن التكنولوجيا ومنصات التوات التوات

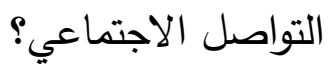
شخصياً لا أعتقد ذلك؛ فقد أظهرت النكتُ، وأظهر

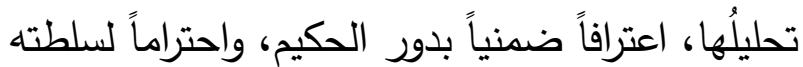

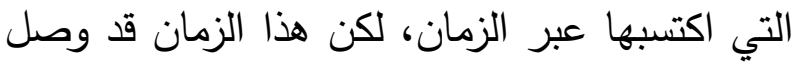
إلى منعطف حتمي يوجب إجراء تعديلات جوهرية التية التيات

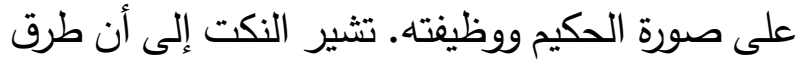
الحكيم التقليدية، والملتوية، لم تعد تجدي في عصر

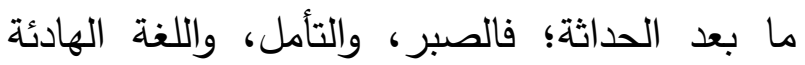
المكثقة، وربما الفصاحة والبديهة اللغوية، لم تعد تفيد في هذا الزمن ولم تعد تتاسبه. فهي لا تعين أبناء هذا

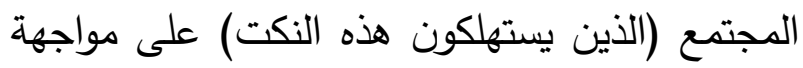
ظروف هذا العصر، ولا تحل مشاكلهم المعقدة، فلم يعد الوقت ترفاً في زمن السرعة الذي نشهده. في مشهد لافت من المسلسل الكوميدي الثهير (واي

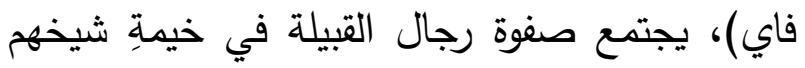

بطريقته التي ربما لا تخلو من حكمة ومن رسالة تدعو

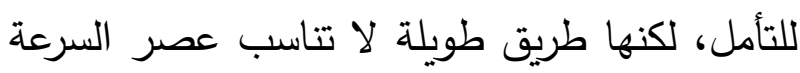
والخفة، ولا تناسب الحدث ولا الزمان ولا المكان. حكيم هذا الزمان هو ذلك الحكيم الذي ييدو فرداً من أفراد

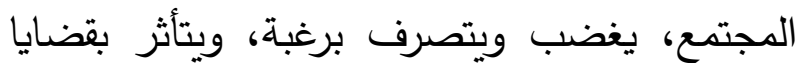

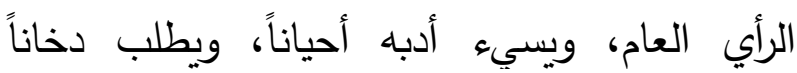

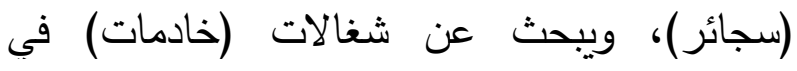
ردضان... الخ. لم تعد صورة المترهبن المتسربل بروح بوذا الصورةً الذهنية المألوفة للحكيم في مجتمع ما بعد الحداثة... لكنه الحكيم الذي يشعر بهم، لأنه مثلهم

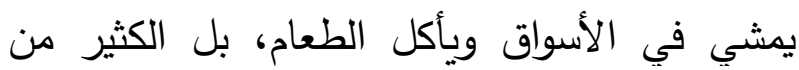
الطعام، حتى تضطره السمنة لعميلة التكميم:

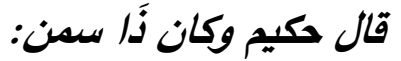

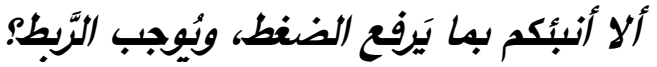
قالوا: أنبئنا! قال: أن يأكل غيرك أضعاف ما تأكل ولا تيسن.

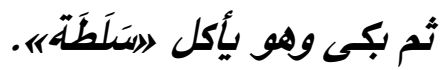
وأنشد قائلاً: بيدّنه الهواء إذا تنفّن وبيسن إن ألى الفول المدمّن

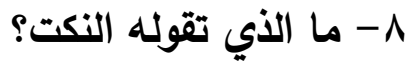
بعد هذا التحليل النصي والسياقي، يبقى السؤال الأهم عن القوى المحركة لهذه النكت، وعما تقوله لنا هذه

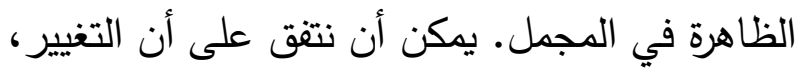

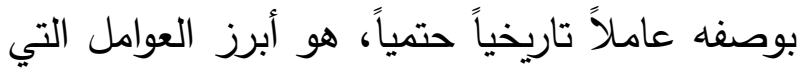
تقف خلف انبثاق الظاهرة وإبقائها حية ومتجددة في الترني المجتمع. وهو تغيير يتجه نحو مشاركة الجمهور في صناعة المعنى، وفي عملية التأويل، وفي تحوير الرسالة (نصية كانت أو ثقافية)، والتحكم في توجياه مسارها

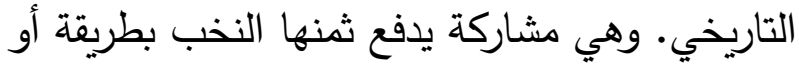


لكنها تزيل وتذيب التوتر في الوقت نفسه. لذلك يعمد

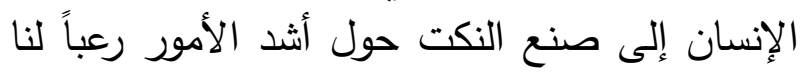
نحن البشر، كالموت مثلاً. في الحقيقة، لقد اكتشفنا

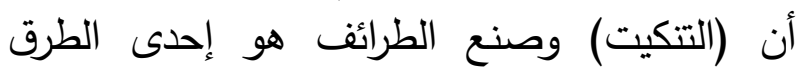

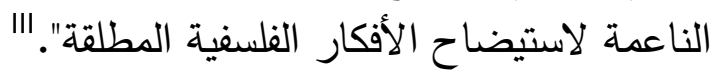
q- الخاتمة

من المهم في سياق وصف هذه الظاهرة التأكيد على عدد من العوامل المؤثرة في بقائها وانتشارها، ويأتي

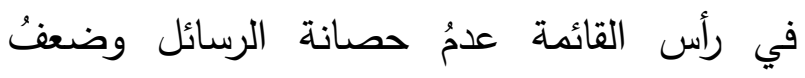
مناعتها، مما يجعلها عرضةً للتغيير والتوجيه والأدلجة دون ممانعة أو مقاومة. من هنا يُلاحظ تغير الصياغة

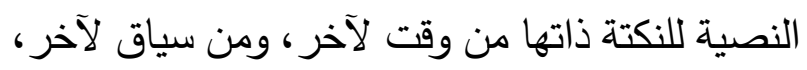

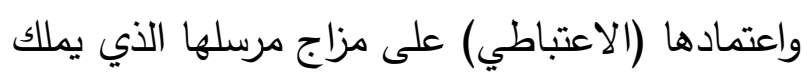

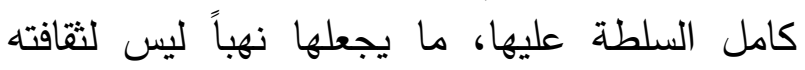
ومستوى تعليمه وحسب، بل لمزاجه اللحظي وآيديولوجيته كذلك. من هنا لوحظ على النكت كثرة

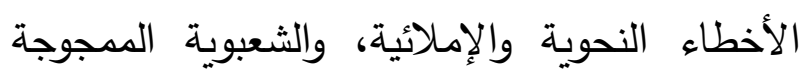
أحياناً، واعتمادها أحياناً على لهجات محلية، وارتباطها

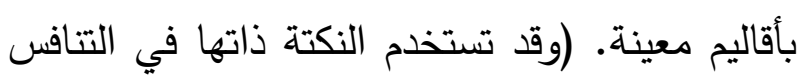

$$
\text { العصبي القبلي فتظهر بأكثر من صورة). }
$$

عدم حصانة النكت يقود أيضاً إلى تدويرها المكرور

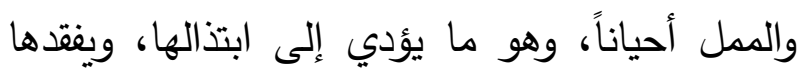

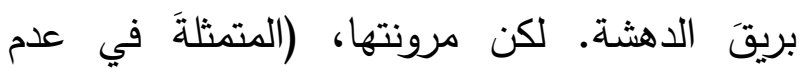

لمناقشة أهم قضاياهم وأخطر قراراتهم. لكن المشهد لا

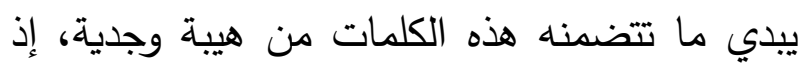
يكتفي رجال القبيلة بالاستماع إلى كلمات شيخهم السخيفة وقصصه الساذجة، والترديد سوياً بإذعان

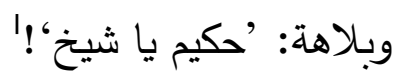
يصور المشهد التبعية الساذجة لرأس السلطة (الثيخ الحكيم)، وما تشير إليه ضمناً من جهل هذا الجمهور وتبعيته العمياء وإرادته المسلوبة. وتقوم النكت بدور مشابه لما يفعله المشهد الكوميدي، لذلك تحمل النكت التهبه بالضرورة نقداً سياسياً/اجتماعياً لاذعاً يبدي رفضاً لأي لئي سلطة تحاول سلبه إرادته وحريته. "منذ بدايات ظهور النكتة الشعبية اقترنت وظيفتها في كثير من الأحيان بالتعبير عن مغزى سياسي يـلامس مجريات الواقع وتداعياته ضمن سياقاته السلبية، فشكلت النكت شكلاً آخر من أشكال التعبير الجماعي عن هموم الجماعة

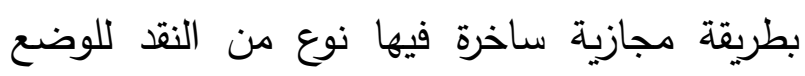
السياسي والاجتماعي القائء". لكن الاعتماد على النكت بطبيعة الحال قد يشير أيضاً إلى الخوف من المواجهة، ومن عواقب المواجهة ربما. وهو وضع يجعل الضحك والسخرية الطريقة الوحيدة

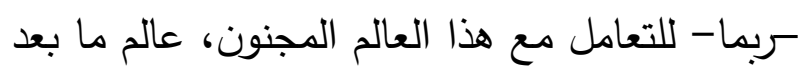

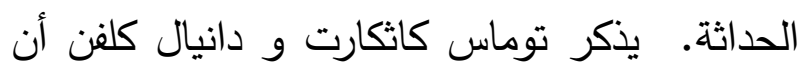
النكت يمكن أن "تتحدث عن أمور محبطة ومقلقة،

$$
\begin{aligned}
& \text { I انظر : واي فاي الموسم ؛_ حكيم يا شيخ، يوتيوب، تاريخ التصفح: ب }
\end{aligned}
$$

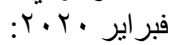

III Cathcart, Thomas \& Klein, Daniel, Heidegger and a Hippo Walk Through Those Pearly Gates: Using Philosophy (and Jokes!) to Explain Life, Death, the Afterlife, and Everything in Between Daniel Martin Klein, (New York, Penguin, 2009) p. 3. 
الجاحظ، عمرو بن بحر. (991)). البيان والتببين. ت: عبدالسلام هارون. القاهرة: مكتبة الخانجي.

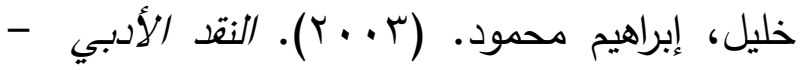

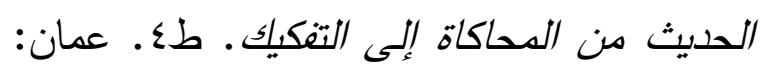
دار المسيرة.

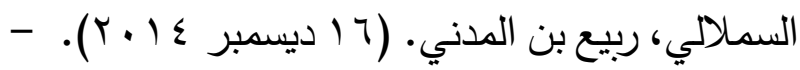
فن الرواية، شبكة الألوكة الأدبية واللغوية. تاريخ التصفح: r فبراير •r.r.

<https://www.alukah.net/literature_lang uage/0/79895/>.

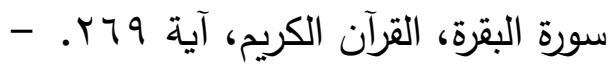

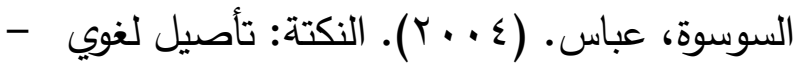

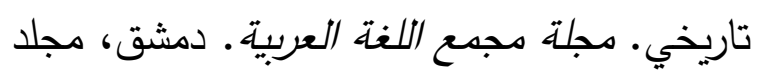

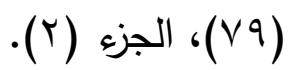

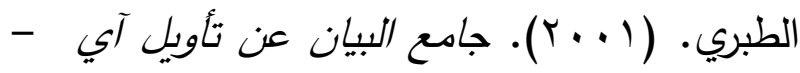
القرآن، تحقيق: عبدالله التركي. القاهرة: دار هجر ، التان . r...

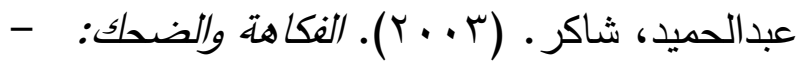
رؤية جديدة. الكويت: عالم المعرفة.

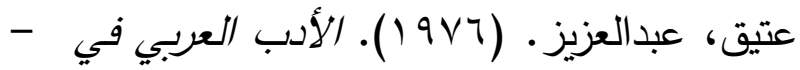
الأندلس. بيروت: دار النهضة.

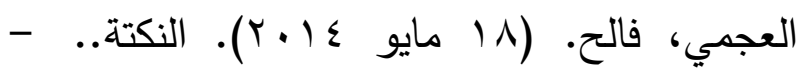
تقويمها ووظائفها. صحيفة اليوم الإلكترونية ـ تاريخ

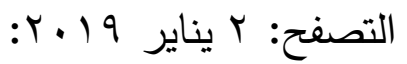
<http://www.alyaum.com/articles/9310 76/>.

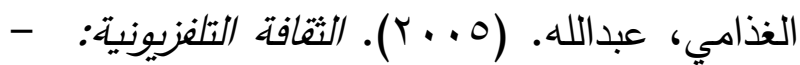
سقوط النخبة وبروز الثعبي. الدار البيضاء: المركز الثقافي العربي.
حصانتها من انتهاك نصيتها، وتكرار تدويرها)، قد

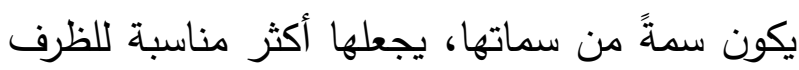
الثقافي الذي ولدت فيه الظاهرة؛ فهي تسمح للجميع أن يتدخل في صياغتها، وفي توجيهها، وتحوير رسالتها. كما أن إرسالها المتكرر يضمن بقاء ها لفترة توفال أطول، وبالتالي تأثيرها كذلك. كما أن مسألة التكرار هذه نسبية في عالم أصبح كل ما فيه نسبيَّ الطبيعة

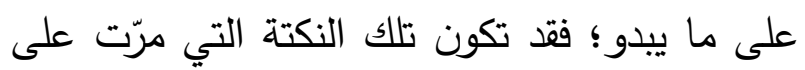
متلقٍ ما عدة مرات في منصات مختلفة، هي نفسها التي تظهر في هاتف متلقِ آخر للمرة الأولى؛ يقرأها،

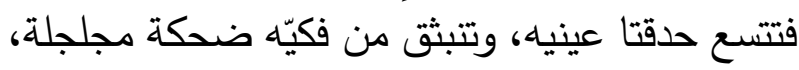

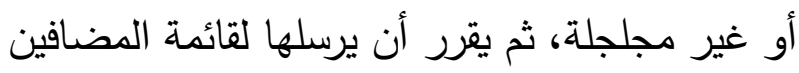

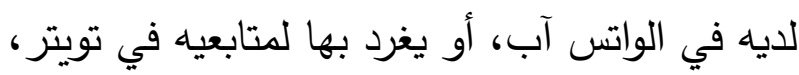

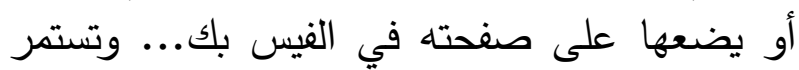

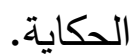

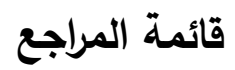

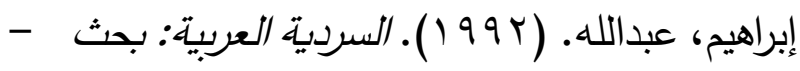
في البنية السردية للموروث الحكائي العربي. بيروت: المركز الثقافي العربي.

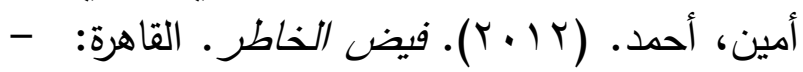
مؤسسة هنداوي للتعليم والثقافة.

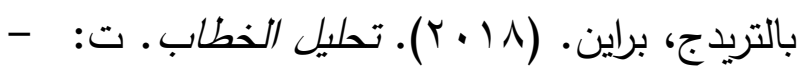

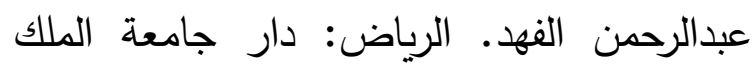

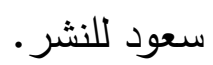

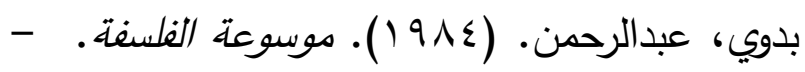
بيروت: المؤسسة العربية للدراسات والنشر .

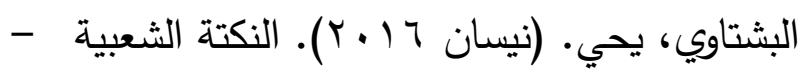
ودورها في النقد السياسي. موقع وزارة الثقافة

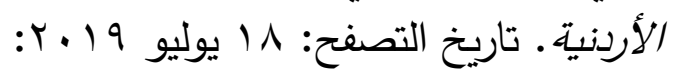
<http://www.ich.gov.jo/sites/default/file s/p2_1.pdf>. 
(2009). Heidegger and a Hippo Walk Through Those Pearly Gates: Using Philosophy (and Jokes!) to Explain Life, Death, the Afterlife, and Everything in Between. New York, Penguin.

C

ohen, Ted. (1999). Jokes: Philosophical Thoughts on Joking Matters. Chicago: University of Chicago Press.

$-$

aughlas, Mary. (1991). Jokes. In Chandra Mukerji \& Michael Schudson (eds.), Rethinking Popular Culture: Contempory Perspectives in Cultural Studies. Berkeley \& LA: Universoty of California Press.

$$
-
$$

Statista: the Statistics Portal, date of access 22 July 2019: <https://www.statista.com/statistics/25 8749/most-popular-global-mobilemessenger-apps/>.

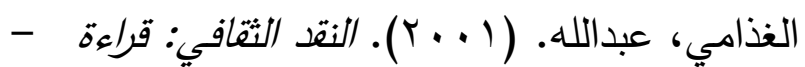

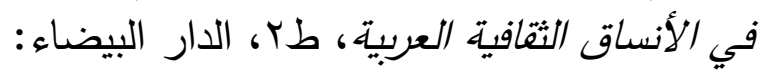

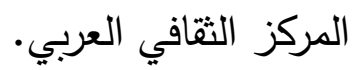

$$
\begin{aligned}
& \text { القيرواني، أبوإسحاق إبراهيم الحصري. }
\end{aligned}
$$

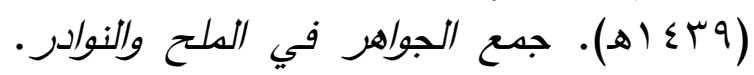

$$
\begin{aligned}
& \text { تحقيق: محمد العزازي. بيروت: دار الكئ الكتب العربية. }
\end{aligned}
$$

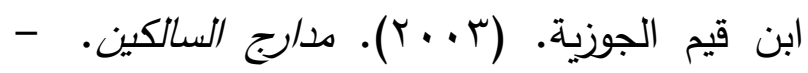

$$
\begin{aligned}
& \text { تحقيق: البغدادي. بيروت: دار الكتاب العربي. }
\end{aligned}
$$

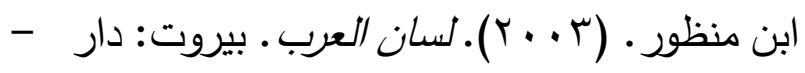

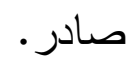

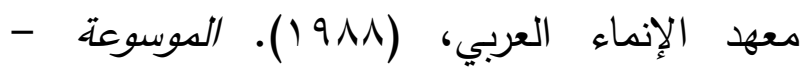

$$
\begin{aligned}
& \text { الفلسفية العربية. }
\end{aligned}
$$

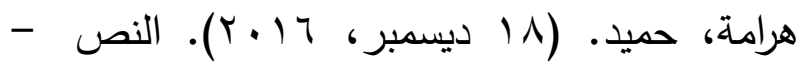

$$
\begin{aligned}
& \text { السردي، موقع الألموكة الإكتروني، تاريخ التصفي جانح }
\end{aligned}
$$

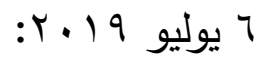

$$
\begin{aligned}
& <\text { http://www.alukah.net/literature_langu } \\
& \text { age/0/110556>. }
\end{aligned}
$$

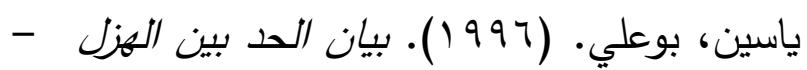

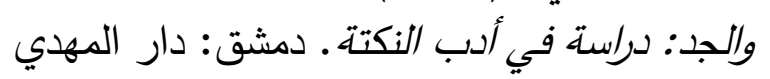

$$
\begin{aligned}
& \text { للثقافة والنشر • الثوي }
\end{aligned}
$$

English References

$-$

C

athcart, Thomas \& Klein, Daniel. 


\title{
The Hunter in his Own Ambush: Image of the Wiseman in Social Media Jokes
}

\author{
Dr. Adel Khamis Alzahrani, \\ Associate Professor of Modern Criticism, Arabic \\ Language \& Literature Dept., King AbdulAziz Univesity, Jeddah. \\ akalzhrani@kau.edu.sa
}

\begin{abstract}
WhatsApp jokes in particular, in order to show how this image has changed. The jokes of wiseman represent a cultural phenomenon in social media platforms; they draw a different picture that is not consistent with the traditional image of the wiseman in Arabic culture, as a person who had always preserved wisdom, dignity, as well as the authority upon the art of speech. This study supposes that this phenomenon implies a discourse, which could be analysed and contextualised.

The subject matter of this research is obviously one of the interests of cultural criticism, which studies literary \& cultural issues in terms of their relation to the masses. Basically, cultural criticism aims at revealing factors $\&$ forces which drive such phenomena, in order to show hidden messages and discourses. Keywords: Jokes, social media, discourse, criticism.
\end{abstract}

